\title{
Diverse Effects of Exosomes on COVID-19: A Perspective of Progress From Transmission to Therapeutic Developments
}

OPEN ACCESS

Edited by:

Jixin Zhong,

Huazhong University of Science and

Technology, China

Reviewed by:

Muhammad Tahir UI Qamar,

Guangxi University, China

Hang Xing,

Rhode Island Hospital, United States

*Correspondence:

Sangiliyandi Gurunathan gsangiliyandi@yahoo.com Jin-Hoi Kim

jhkim541@konkuk.ac.kr

Specialty section: This article was submitted to Inflammation,

a section of the journal

Frontiers in Immunology

Received: 28 May 2021 Accepted: 05 July 2021

Published: 28 July 2021

Citation:

Gurunathan S, Kang MH and Kim J-H (2021) Diverse Effects of Exosomes on

COVID-19: A Perspective of

Progress From Transmission to

Therapeutic Developments.

Front. Immunol. 12:716407.

doi: 10.3389/fimmu.2021.716407

\author{
Sangiliyandi Gurunathan *, Min Hee Kang and Jin-Hoi Kim* \\ Department of Stem Cell and Regenerative Biotechnology, Konkuk University, Seoul, South Korea
}

Severe acute respiratory syndrome coronavirus 2 (SARS-CoV-2) is a new strain of coronavirus and the causative agent of the current global pandemic of coronavirus disease 2019 (COVID-19). There are currently no FDA-approved antiviral drugs for COVID-19 and there is an urgent need to develop treatment strategies that can effectively suppress SARS-CoV-2 infection. Numerous approaches have been researched so far, with one of them being the emerging exosome-based therapies. Exosomes are nano-sized, lipid bilayer-enclosed structures, share structural similarities with viruses secreted from all types of cells, including those lining the respiratory tract. Importantly, the interplay between exosomes and viruses could be potentially exploited for antiviral drug and vaccine development. Exosomes are produced by virus-infected cells and play crucial roles in mediating communication between infected and uninfected cells. SARS-CoV-2 modulates the production and composition of exosomes, and can exploit exosome formation, secretion, and release pathways to promote infection, transmission, and intercellular spread. Exosomes have been exploited for therapeutic benefits in patients afflicted with various diseases including COVID-19. Furthermore, the administration of exosomes loaded with immunomodulatory cargo in combination with antiviral drugs represents a novel intervention for the treatment of diseases such as COVID-19. In particular, exosomes derived from mesenchymal stem cells (MSCs) are used as cell-free therapeutic agents. Mesenchymal stem cell derived exosomes reduces the cytokine storm and reverse the inhibition of host anti-viral defenses associated with COVID-19 and also enhances mitochondrial function repair lung injuries. We discuss the role of exosomes in relation to transmission, infection, diagnosis, treatment, therapeutics, drug delivery, and vaccines, and present some future perspectives regarding their use for combating COVID-19.

Keywords: exosomes, SARS-CoV-2, COVID-19, therapeutics, vaccines 


\section{INTRODUCTION}

Coronavirus disease 2019 (COVID-19), caused by the severe acute respiratory syndrome coronavirus 2 (SARS-CoV-2) was first reported in Wuhan, China, in December 2019, and is now the worst pandemic in history. The SARS-CoV-2 outbreak has the potential to become a long-lasting global health crisis. As of February 3, 2021, the number of individuals infected with the novel coronavirus has surpassed 112,726,316 globally, with over 2,498,395 deaths and more than 88,298,471 recoveries (https:// covid19.who.int). SARS-CoV-2 belongs to the group of viruses called coronaviruses $(\mathrm{CoVs})$, which constitute a large group of potentially pathogenic RNA viruses typically associated with respiratory diseases. These viruses cause a variety of diseases in mammals and birds and are able to cross between species, causing serious respiratory pathologies in humans such as Middle East respiratory syndrome (MERS), severe acute respiratory syndrome (SARS), and COVID-19. The structure of their spike proteins gives them the appearance of a crown because of which these viruses are referred to as CoVs. COVID19 is more contagious than SARS-CoV, MERS, swine acute diarrhea syndrome (SADS), and other severe viral diseases including ebola virus disease and influenza, due to its ease of spread (1). The primary site of SARS-CoV-2 infection in the human body is the lungs, and it leads to various distresses to various organs. The primary symptoms of COVID-19 are fever, dry cough, and fatigue. The incubation period of SARS-CoV-2 is approximately 14 days.

SARS-CoV-2 is a spherical with an average size ranges from 80 to $120 \mathrm{~nm}$ in diameter (2). During virus internalization, $\mathrm{S}$ proteins bind to the angiotensin converting enzyme 2 (ACE2) receptors on the host cell, and transmembrane protease serine 2 (TMPRSS2) primes the $\mathrm{S}$ protein for internalization by fusion with the host membrane (3). SARS-CoV-2 replication takes place through sequential processes. During the first stage, viral genes enter the host cell and are subsequently cause the production of viral polypeptides, which then assemble into viral proteins that are required to form the viral core and surface $S$ protein. The virus then matures, replicates, and leaves the host cells to infect new cells (4).

\footnotetext{
Abbreviations: ACE2, angiotensin converting enzyme 2; Abs, apoptotic bodies; bmMSCs, bone marrow mesenchymal stem cells; COVID-19, coronavirus disease 2019; CoVs, coronaviruses; DPP4, dipeptidyl peptidase 4; DMVs, doublemembrane vesicles; ER, endoplasmic reticulum; ESCRT, endosomal sorting complex required for transport; E, envelope; EDMV, extracellular doublemembrane vesicle; exRNAs, extracellular RNAs; EVs, extracellular vesicles; HBV, hepatitis B virus; HCV, hepatitis C virus; hiPSC-CMs, human induced pluripotent stem cell-derived cardiomyocytes; HUMSCs, human umbilical cordderived MSCs; IFN- $\gamma$, interferon gamma; IFNs, interferons; ILVs, intraluminal vesicles; IncRNAs, long non-coding RNAs; $\mathrm{M}$, membrane; mRNA, messenger RNA; miRNA, microRNA; MVs, microvesicles; MERS, Middle East respiratory syndrome; MSCs, mesenchymal stem cells; MVBs, multivesicular bodies; nAbs, neutralizing antibodies; $\mathrm{N}$, nucleocapsid protein; $\mathrm{RBD}$, receptor-binding domain; SARS, severe acute respiratory syndrome; siRNAs, small interfering RNAs; S, spike protein; SADS, swine acute diarrhea syndrome; TEMs, tetraspanin-enriched microdomains; WHO, World Health Organization; TF, tissue factor; TTSP, type II transmembrane serine protease; IL-6, interleukin-6; BBB, blood-brain barrier.
}

Extracellular vesicles (EVs) are nano-sized particles produced by all cell types and it contains soluble molecules such as proteins and nucleic acids such as microRNA (miRNA) and messenger RNA (mRNA) (5). EVs such as exosomes are small, lipid membrane-enclosed, heterogeneous membrane vesicles secreted into various biological fluids. The size of the exosomes depends on their cellular origin. According to the International Society of Extracellular Vesicles, EVs comprise three types of vesicles: exosomes, microvesicles (MVs), and apoptotic bodies (5). Exosomes contain various types of biomolecules help deliver to target cells to reprogram the fate, function, and morphology of the target cells (6-8). Exosomes were originally described as a tool for removing unwanted compounds from cells (9), however later studies have discovered that exosomes are essential for intercellular communication and are involved in various types of diseases including infectious diseases and cancer (7). The presence of exosomal protein determines their origin and varies depending on the types of host cell. The cargo of exosome is RNA, mRNAs, miRNAs, and other noncoding RNAs play significant role in signaling diversity. Exosomal miRNA selectively distributed into exosomes and it expression can alter under physiological or pathological conditions $(10,11)$. Exosomes carry certain lipids such as cholesterol, sphingolipids, phosphoglycerides, ceramides, and saturated fatty acid chains, which are play an essential role in maintaining the biological activity and maintain their stability, and facilitating the process of internalization (12). Exosomes contains various types of cargo such as proteins which enables surface display of proteins and tissue targeting; siRNA is used to disrupt genes of interest in genetic therapy and miRNA-loaded exosomes are used to modify the expression of specific genes, thereby treating specific diseases (13). Exosomes play an important role in the progression of various pathological conditions (14). Exosomes can transfer viral particles from infected cells to healthy cells and modulate host immune responses (15). Several studies have demonstrated that exosomes play a crucial role in viral infections of the lungs and respiratory tract (16), inflammation $(17,18)$, and injury (19). The similar structural and physicochemical properties of exosomes and viruses, facilitate the entry, biogenesis, and multiplication of the viruses in the host cells ${ }^{16 .}$ Viruses and exosomes share various common features such as size, structure, biochemical composition, and mechanisms of biomolecule transport within the cells $(20,21)$. Mesenchymal stem cells (MSCs) and MSCderived exosomes are potentially beneficial for COVID-19 therapy. Exosomes are superior, simpler, and more clinically convenient compared to their parental MSCs (22). Due to the inherent properties of EVs in relation to immunomodulation, wound healing, and drug delivery, EVs represent a valuable approach for antiviral therapeutics, including COVID-19 (4). Polak et al. engineered EV-based vaccine platforms displaying native viral envelope proteins embedded in EVs and stimulating a robust anti-SARS-CoV-2 response in mice (23).

Various treatment modalities have been developed to overcome the morbidity and mortality associated with COVID-19 (24). Vaccination and convalescent plasma could be efficient treatment options; however, stable viral epitopes are 
required for their efficacy. Due to the high rate of mutation of SARS-CoV-2, it can directly suppress host T cell function, which renders therapies ineffective (25). MSC-derived exosomes showed promising results in treating severe COVID-19 patients who were already receiving hydroxychloroquine and azithromycin treatment (26). Exosome treatments resulted in $71 \%$ of the patients recovering from COVID-19. "Secreted by bone marrow mesenchymal stem cells (bmMSCs)" are novel, multitargeted, next-generation biological agents composed of a complex mix of signaling nanovesicles that can prevent cytokine storm and reverse the suppression of host antiviral defenses, which is characteristic of SARS-CoV-2 infection (27). Exosomes play a significant role in viral infections and infected cells release more vesicles. The interesting interplay between exosomes and viruses has led to the exploitation of exosomes as novel therapeutics. Hence, this review aims to discuss the role of nanosized vesicles in relation to transmission, infection, diagnosis, treatment, therapeutics, drug delivery, and exosomebased vaccines.

\section{ROLE OF EXOSOMES ON TRANSMISSION, INFECTION AND HOST CELL RESPONSE IN COVID-19}

SARS-CoV-2 belongs to the family Coronaviridae and genus Betacoronavirus, which comprise enveloped, positive-sense single-stranded RNA viruses (28). The SARS-CoV-2 genome sequence shares approximately $80 \%$ and $50 \%$ sequence identity with SARS CoV and MERS-CoV, respectively $(29,30)$. The SARS-CoV-2 genome encodes four main proteins, namely $\mathrm{S}$, envelope (E), membrane $(M)$, and nucleocapsid $(N)$ proteins, in addition to several accessory proteins.26 The $\mathrm{S}$ protein has a receptor-binding domain (RBD) that is responsible for binding to ACE2. TMPRSS2 facilitates viral entry at the plasma membrane, whereas cathepsin $\mathrm{L}$ activates the $\mathrm{S}$ protein in endosomes and can compensate for entry into cells that lack TMPRSS2 (3). SARS-CoV-2 enters the human system through interactions between the host dipeptidyl peptidase 4 (DPP4, CD26) protein and viral $S$ glycoprotein. The viral RNA is subsequently synthesized in virus-induced double-membrane vesicles (DMVs) in the cytoplasm of the infected cells. The DMVs contain RNA transported through secretory vesicles that is released by exocytosis (31). Histopathological studies revealed that SARS-CoV-2 is located within the vacuoles or DMVs of host cells and found that SARS-CoV-2 was localized as clusters of coronavirus-like particles with distinctive spikes in the renal tubular epithelium $(32,33)$. The primary site of SARS$\mathrm{CoV}-2$ infection appears to be the lung, which may be a source of viral spread to other organs such as the kidneys, intestines (34), and bladder (35). Recent studies have suggested that SARS-CoV2 infects blood vessels prior to other tissues (36). SARS-CoV and SARS-CoV-2 share a similar mechanism of viral assembly near the rough endoplasmic reticulum (ER) (37). These findings suggest that the exosomal pathway may be involved in the transport of SARS-CoV-2. SARS-CoV and SARS-CoV-2 infect and release free viral particles to adjacent cells and tissues, and expand to circulate systemically, reaching distant tissues and various organs including the vascular system by establishing targets through fibrin-rich hyaline membranes $(20,36,38,39)$

Viral spread and anchoring to host cells depend on the susceptibility and permissiveness of the host cell. Of all the organs, the lungs are the primary target of SARS-CoV-2. During SARS-CoV-2 infection of the lung, ACE2 expression (mRNA and protein) is induced by type I and II interferons (IFNs) $(40,41)$. SARS-CoV-2 pathogenicity increases upon the mutation of the $\mathrm{S}$ protein $\mathrm{RBD}$, which makes close contact with ACE2 (29, 42, 43). Exosomes play critical roles in SARS-CoV-2 transmission and viral load, as demonstrated by the requirement of the endosomal sorting complex required for transport (ESCRT) machinery, which promoted the SARS-CoV-2 life cycle in a small population of human type II alveolar cells, suggesting that SARS-CoV-2 hijacks a small population of type II alveolar cells with high expression of ACE2 and other proviral genes for its productive replication (Figure 1) (44). Functional polybasic (furin) cleavage site (RRAR) plays a significant role in the cleavage of RRAR at the S1/S2 cleavage site in the $S$ protein $(3,45)$. Similar to SARS, SARS-CoV-2 is transmitted through respiratory droplets, direct contact with contaminated surfaces, fecal-oral transmission (46-48), and respiratory routes $(29,49)$ such as active coughing (50-52). Enveloped viruses and exosomes use similar pathways for host-cell fusion and biogenesis of virion particle at the plasma membrane (Figure 2). Viruses require cell-surface receptors for entry into the host cells, and are able to transfer these required receptors to receptor-null cells, thereby increasing the number of cells that they can infect $(53,54)$. Among the various cellular receptors, integrins are suitable receptors for attachment and/or cell entry of both non-enveloped and enveloped viruses (55). The tripeptide Arg-Gly-Asp (RGD) motif of SARS-CoV binds to integrin, which serves as an alternate receptor, facilitating viral transmission and pathology (56). Similarly, circulating exosomes are thought to bind to the cell membrane of target cells through various adhesion molecules (57-61). Exosomes enriched with tetraspanin-enriched microdomains (TEMs) could represent an alternative route of endocytosis for exosome fusion. For example, $\mathrm{CoV}$ proteolytic priming takes place in TEM microdomains, suggesting that blocking tetraspanin function by antibodies may inhibit $\mathrm{CoV}$ infection (62). The pathogenesis of SARS-CoV-2 starts through binding to epithelial cells in the respiratory tract, SARS- CoV-2 starts replicating and migrating down to the airways and enters alveolar epithelial cells in the lungs and initiates replication and eventually trigger strong immune response. coronavirus infections increased circulating exosomes containing lung-associated self-antigens as well as viral antigens and $20 \mathrm{~S}$ proteasome. These findings suggest that COVID-19 virus infected cells produce exosomes containing virus particles.

Exosomes are a subset of extracellular vesicles involved in various physiological and pathological functions. Exosomes are endocytic vesicles derived from yeast that share the morphology and biochemical features of eukaryotic exosomes and play a role 


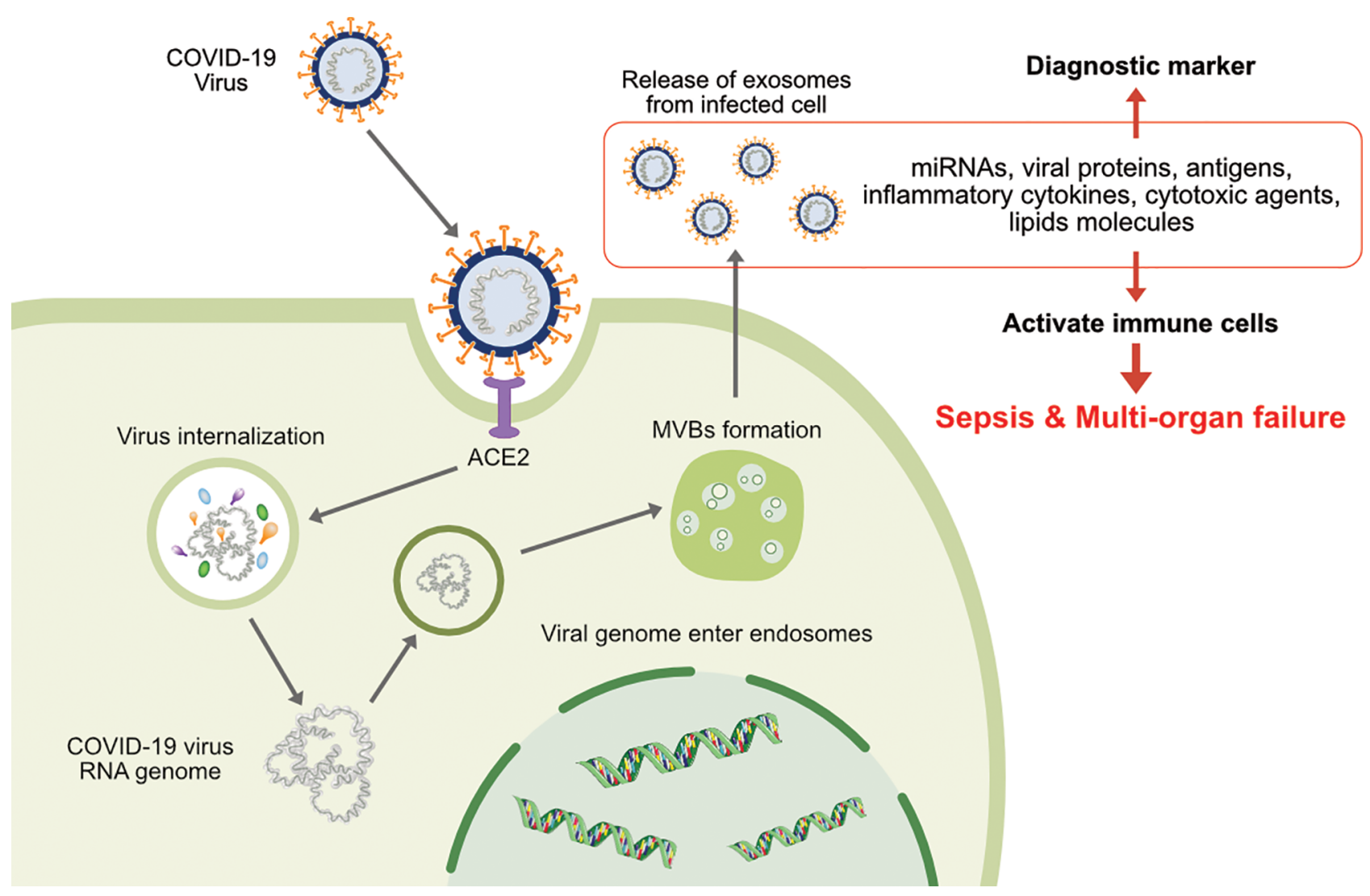

FIGURE 1 | The involvement of exosomes on transmission, infection and release of virion particles and contents of diagnostic makers of COVID-19.

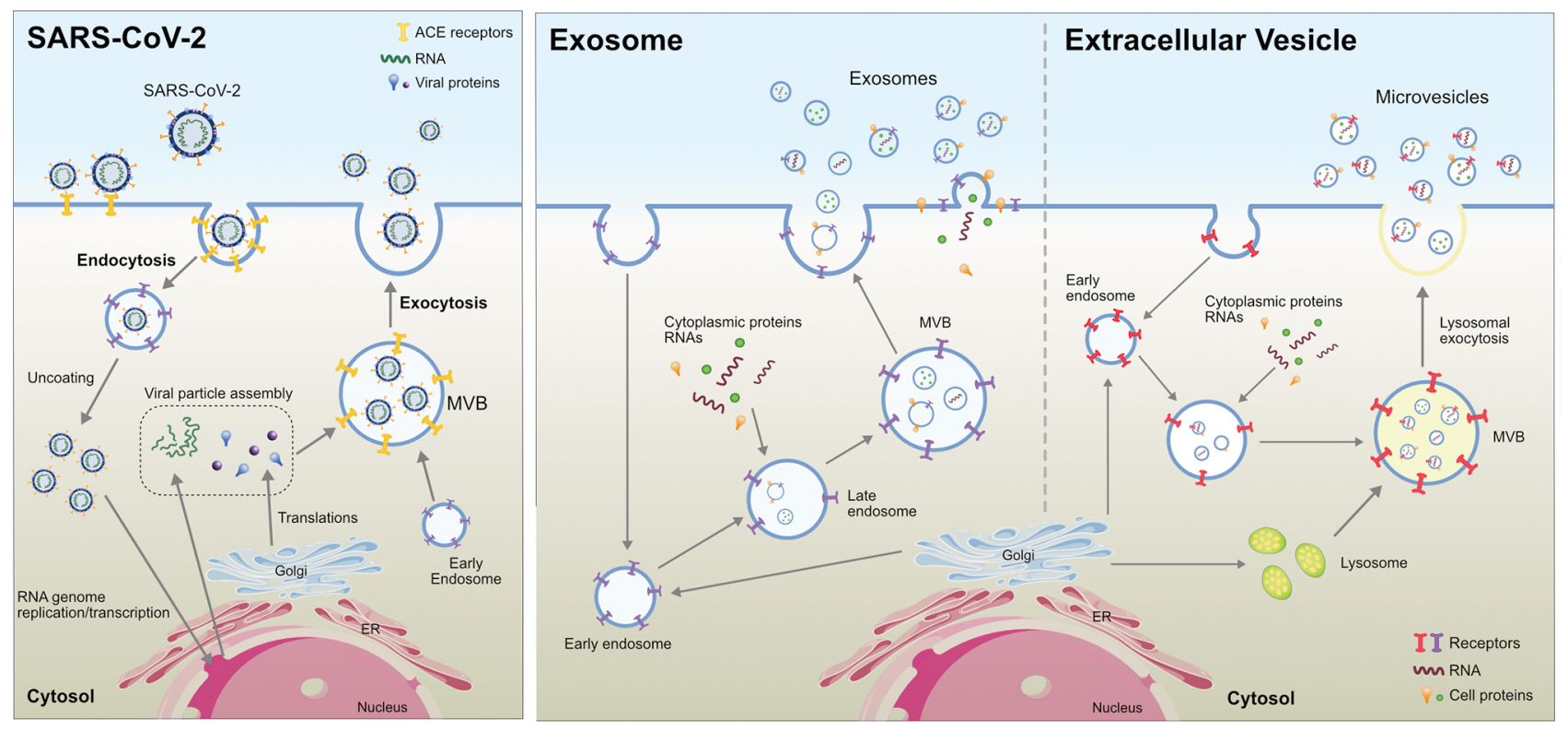

FIGURE 2 | Comparison between Extracellular Vesicle, Exosome and virion biogenesis at the plasma membrane in eukaryotic cells. 
in endocytic and exocytic pathways $(63,64)$. Exosomes are formed by an inward budding of the membranes of the multivesicular bodies (MVBs), thereby creating intraluminal vesicles (ILVs) inside MVBs (6). Exosome biogenesis is controlled by the ESCRT machinery located at the MVB membrane, which is responsible for the generation of ILVs. Exosome biogenesis is regulated by both ESCRT-dependent and -independent mechanisms. Several tetraspanins that are enriched in the exosomal membrane facilitate SARS-CoV-2 cellular entry. The interaction between CD9 and TMPRSS2 favors the entry and infection of MERS in murine lungs (65). The phosphatidylserine groups of exosomes and viruses share similar structural features on their surface $(66,67)$. Exosomes are able to transfer ACE2 to recipient cells, which support virus internalization and infection (68). Many viruses are known to enter the extracellular double-membrane vesicle (EDMV) or exosome avenue during synthesis and intra-host spreading (69). Human lung epithelial cells are susceptible to SARS-CoV2 infection and can release exosomes containing viral components, facilitating the transmission of the SARS-CoV-2 genome into human-induced pluripotent stem cell-derived cardiomyocytes (hiPSC-CMs). The uptake of exosomes harboring viral RNA leads to the upregulation of inflammation-related genes in hiPSC-CMs. These findings suggest that SARS-CoV-2 RNA-containing exosomes represent an indirect route of viral RNA entry into cardiomyocytes (70).
Circulating $\mathrm{ACE}^{+}$exosomes in plasma from both healthy donors and patients who recovered from COVID-19 inhibited SARS-CoV-2 infection by blocking the binding of the viral S protein to its cellular receptor (71). For instance, HIV uses this machinery during cellular infection by packing viral proteins and RNA into vesicles that are later released into the extracellular space, thereby contributing to the spread of the virus to noninfected cells (72). However, this phenomenon has not yet been demonstrated in SARS-CoV-2 (73).

Exosomes are sub-set of extracellular vesicles which are playing a significant role in intercellular communication and regulation. During viral infection, vesicles serve as antigens or agonists of innate immune receptors to induce host defense and immunity, or serve as regulators of host defense and mediators of immune evasion (74). Exosomes produced by infected cells usually have a molecular signature that is distinct from that of healthy cells. Extracellular vesicles or exosomes are internalized into the recipient cells through various processes such as phagocytosis, macropinocytosis, endocytosis and fusion. Viruses and exosomes share several common biogenesis features, and both transport biomolecules including RNA, lipid and proteins (Figure 3) (75). Many viruses enter the host cells and spread through the EDMV or exosomes (69). Recent studies have shown that upon SARS-CoV infection of AT2 cells, viral particles can be seen within EDMVs $(31,76)$. Coronavirus RNA is synthesized in virus-induced DMVs in the cytoplasm of

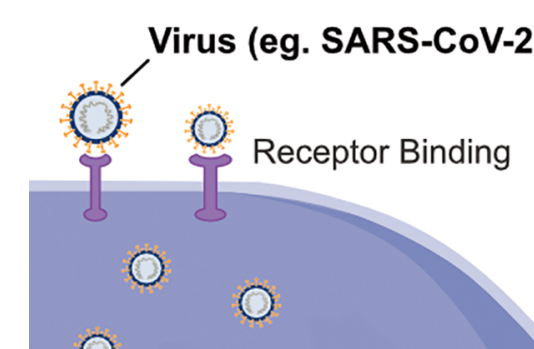

o

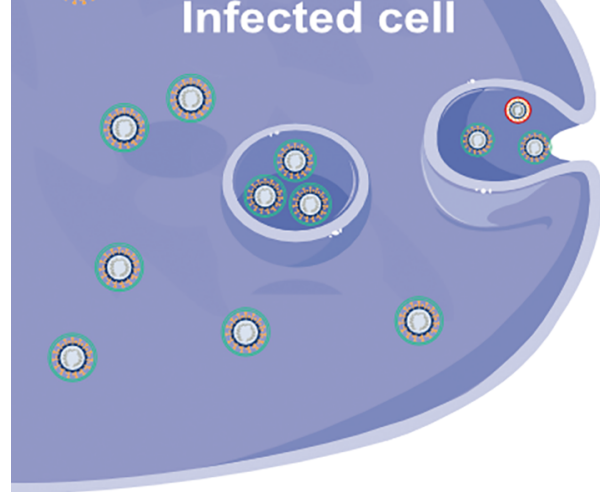

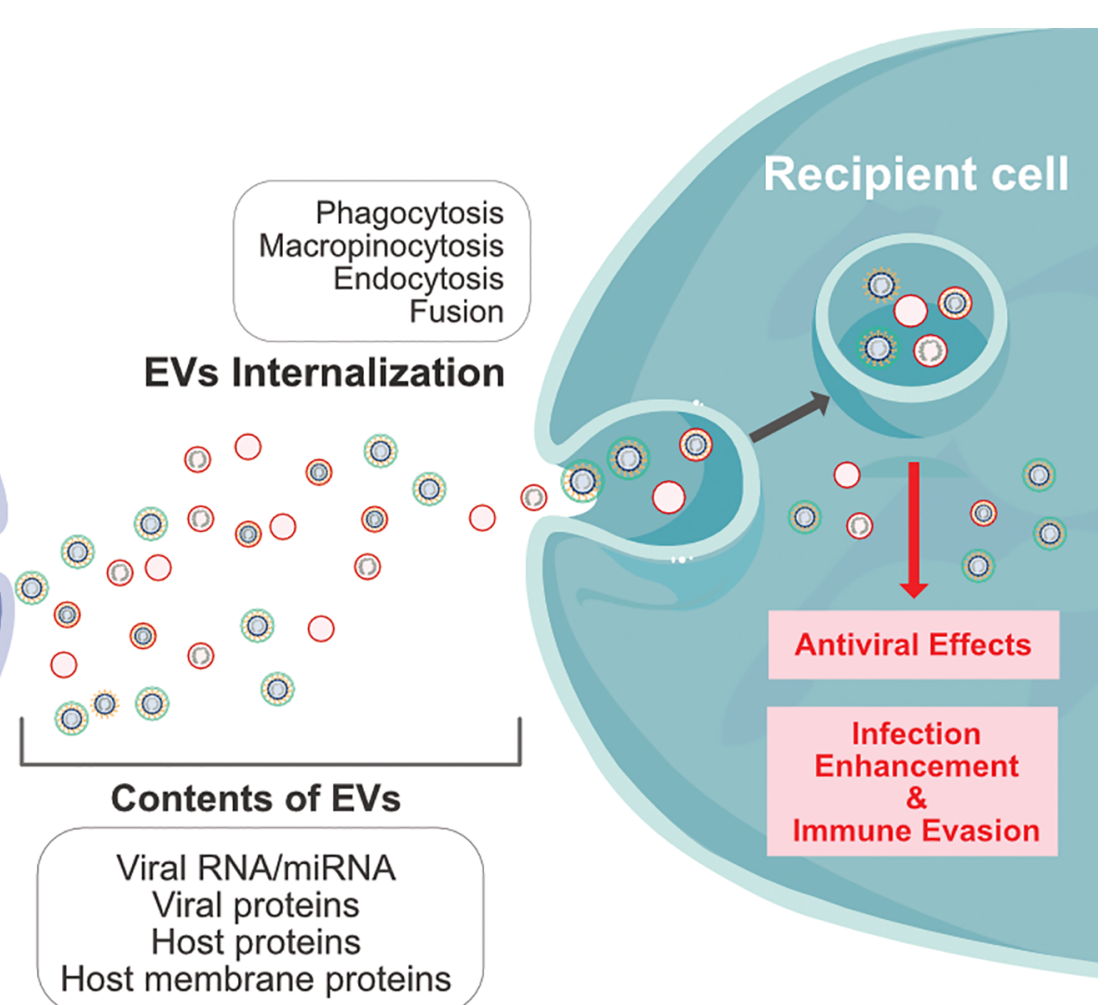

FIGURE 3 | Schematic diagram represents interplay between infected cells and recipient cells through extracellular vesicles by various processes such as phagocytosis, macropinocytosis, endocytosis and fusion of viral particles. 
infected cells. Viral particles are transported through the cytoplasm in secretory vesicles and are released from cells by an exocytic process, and SARS-CoV-2 is present within the vacuoles or DMVs within the host cells $(32,33)$. SARS-CoV-2 assembly is similar to that of SARS-CoV and has been found near the rough ER (32).

Coronavirus spike proteins are categorized as class I fusion proteins (77). Most coronaviruses require two different triggering agents for fusion, receptor binding, and intracellular proteolytic cleavage following the proteolysis of receptor-bound viral ligands (78). The coronavirus receptors are transmembrane glycoproteins that facilitate susceptibility to infection $(79,80)$. Coronaviruses interact with and enter host cells through DPP4 (CD26). Proteases are essential for infection and are intracellularly connected with the type II transmembrane serine protease (TTSP) family $(81,82)$. For example, TTSP family members such as TMPRSS2 cleave coronavirus $\mathrm{S}$ proteins to form unlocked and fusion-catalyzing structures at the cell surface to mediate rapid entry $(81,82)$. After cellular entry, various glycoproteins facilitate fusion $(83,84)$. It has been suggested that several tetraspanins, which are enriched in the exosomal membrane, may participate in coronavirus fusion events $(8,85)$. Both tetraspanin CD9 and TMPRSS2 facilitate MERS coronavirus entry and a robust infection of mouse lungs in vivo (65). Exosomal CD9 molecules play an important role in loading cargo into exosomes, which could be important in loading SARS-CoV-2 proteins. Coronavirus infection increases the levels of circulating exosomes containing lung-associated self-antigens as well as viral antigens and the $20 \mathrm{~S}$ proteasome (86). These findings support the idea that SARS-CoV-2-infected cells could produce exosomes with increased amounts of virus particles. The stronger affinity between SARS-CoV-2 and ACE2 could promote infection and viral spread (87). TMPRSS2mediated cleavage of the $\mathrm{S}$ protein is essential for SARS-CoV-2 entry, and exosome-mediated transfer of ACE2 increases SARSCoV-2 entry and infection $(68,88)$. Gunasekaran et al. found that exosomes derived from virus-infected cells induced the host humoral and cellular immune response by transferring viral and self-antigens (89). These studies demonstrate that exosomes play a significant role not only in sorting ACE2 but also in sorting other cargo such as miRNAs and proteins, which similar in case of other viruses, can be transferred to healthy cells. Krishnamachary et al. reported that exosomes function as causative agents for COVID-19 by altering the proinflammatory, coagulopathy, and endothelial injury protein cargo (90). Exosomes play significant role in COVID-19 recurrence, and thus may interact with the expression of circRNA and lncRNA. GO and KEGG enrichment analysis show that differentially expressed circRNA and lncRNA are mainly involved in the regulation of host cell cycle, apoptosis, immune inflammation, signaling pathway and other processes. The comparison to exosomes related databases shows that there are 114 differentially expressed circRNA, and 10 differentially expressed lncRNA related to exosomes (91). While SARS-CoV-2 infects the cells, host cells release exosomes and other extracellular vesicles carrying viral and host components that can modulate the immune response. Barberis et al. (92) reported that SARS-CoV-2 infection modulates exosome content, exosomes' involvement in disease progression, and the potential use of plasma exosomes as biomarkers of disease severity. A proteomic analysis of patient-derived exosomes containing proteins are involved in the immune response, inflammation, and activation of the coagulation and complement pathways, which are the main mechanisms of COVID-19-associated tissue damage and multiple organ dysfunctions. Gambardella et al. (93) reported that exosomal microRNAs may drive thrombosis in COVID-19 patients and GM3-enriched exosomes positively correlated with severity of disease in COVID-19 conditions (94).

Recently, findings from Barberis et al. (92) suggest that circulating exosomes are potentially involved in the processes associated with SARS-CoV-2 infection. In addition, Bioinformatics analysis revealed the presence of proteins in exosomes are involved in coagulation process, transport activity, complement activity, protease inhibitor activity, and defense/ immunity protein activity. Exosomes derived from respiratory syncytial virus-infected cells were able to activate an innate immune response by inducing cytokine and chemokine release from human monocytes and airway epithelial cells (95). Coronaviruses such as SARS and MERS infected patients exhibited high levels of pro-inflammatory cytokines and chemokines associated with pulmonary inflammation and extensive lung involvement (96). Jamilloux et al. (97) reported that rapid activation of the innate immune response leads to an elevation in acute-phase reactants among patients with COVID-19, including ESR, C-reactive protein (CRP), serum amyloid A, and ferritin. Several studies reported that SARS-CoV-2 infected patients are proteins are involved in platelet degranulation (98), together with the low platelet count associated with severe COVID-19 and mortality $(99,100)$. SARS-CoV-2 infected patients increase the level of IL-6, which is also could affect protein secretion from cells through EVs (101). The SARS-Co-V-2 infected patients induce cellular response and eventually lead to cytokine storm and the presence of TNF, IL-1 $\beta$, and IL-6 (102). Hence, circulating exosomes are potentially involved in SARS-CoV-2 infected patients to induce various cellular responses such as severity of disease, tissue damage and multiple organ dysfunctions.

\section{EXOSOMES AS DIAGNOSTIC BIOMARKERS OF COVID-19}

Exosomes and extracellular RNAs (exRNAs) are involved in several pathological processes. Most exRNAs are protected from degradation in bio-fluids via incorporation into exosomes or into complexes with lipids and proteins. Different types of exRNAs (eg, mRNAs, miRNAs, small nuclear RNAs, transfer RNAs, lncRNAs) are produced and released during antiviral responses, playing fundamental roles in modulating the host innate immune system. These exRNAs are involved in a complex network of interactions between the virus and infected host 
cells (103). Fujita et al. identified three potential early biomarkers for COVID-19, including antiviral response-related EV proteins, coagulation-related markers, and liver damage-related exRNAs (104). Among these markers, EV COPB2 had the best predictive value for the severe deterioration of COVID-19 patients in this cohort. Due to their ease of isolation, stability, and ease of storage, exosomes are excellent biomarkers for the detection of infection from minimally- or non-invasive biological samples (105). Exosomal-miRNA is used to monitor chronic hepatitis B virus $(\mathrm{HBV})$ infection. Hepatitis $\mathrm{C}$ virus $(\mathrm{HCV})$ alters the miRNA cargo of exosomes, which contains a complex of HCV RNA with Ago2, HSP90, and miR-122 (90). Exosomes derived from SARS-CoV-2-infected cells contain specific proteins that serve as important biomarkers for the disease. Kim et al. cultured subgenomic SARS-CoV-2 RNAs in Vero cells (9). High levels of the S (Orf2), Orf3a, E (Orf4), M (Orf5), Orf6, Orf7a, and N (Orf9) proteins, and low levels of Orf7b were observed within the subgenomic RNAs (106). Another study by Wölfel et al. found that the presence of the $\mathrm{E}$ gene subgenomic RNA indicates active viral infection and transcription (107). Alexandersen et al. detected SARS-CoV-2 subgenomic RNAs in diagnostic samples, indicating that these samples are not suitable indicators of active coronavirus replication or infection (108). SARS-CoV-2 induces tissue factor (TF) expression and increases levels of circulating TF-positive EVs, which could contribute to thrombosis in patients with COVID-19. EV-TF activity was also associated with disease severity and mortality (104). Electron microscopy revealed the early formation and accumulation of typical DMVs containing viral replication complexes associated with SARS-CoV-2 (109). A proteomic analysis of patient-derived exosomes containing proteins are serving as potential biomarkers such as fibrinogen, fibronectin, complement $\mathrm{C} 1 \mathrm{r}$ subcomponent and serum amyloid P-component. Furthermore, circulating exosomes are playing significant role in inflammation, coagulation, and immunomodulation-during SARS-CoV-2 infection (92).

\section{THERAPEUTIC STRATEGY OF USING EXOSOMES FOR TREATING COVID-19}

Effective therapies are still unavailable for COVID-19 patients. However, recent clinical investigations have made significant advances to find suitable, effective, and affordable therapeutic solutions for the various forms of COVID-19, caused by various mutant strains. Unfortunately, patients with underlying diseases such as heart disease and diabetes are at high risk for COVID-19. Although exosomes facilitate SARS-CoV-2 infection, they may be paradoxically advantageous for the treatment of COVID-19. Inhibition of exosome uptake by neighboring cells is another strategy to limit virus spread (110). Several strategies have been adopted to develop suitable treatments for COVID-19, including MSCs and MSC-derived exosomes. For instance, MSCs can produce various cytokines and paracrine factors that can directly interact with immune cells, including $\mathrm{T}$ cells, B cells, dendritic cells, macrophages, and natural killer cells. These characteristics give MSCs their immunomodulatory abilities. This immunomodulatory effect could help inhibit the overactivation of the immune system $(4,106)$. In particular, MSCs can prevent the cytokine storm associated with COVID19. Recently, clinical studies have revealed that the application of human umbilical cord-derived MSCs (HUMSCs) showed a positive response in COVID-19 patients $(107,111,112)$. Leng et al. found that MSC transplantation considerably improved the pulmonary function of patients with SARS-CoV-2-related pneumonia over a period of two days (107). However, MSC transplantation is associated with some undesired side effects; therefore, finding alternative solutions involving MSC-derived products, such as secretomes and exosomes, is essential. Secretomes and exosomes can interact with target cells through ligand receptor binding or by internalization, to modulate cellular responses, and secretome-based therapy shows promise for treating COVID-19 patients (113-115). Exosomes isolated from the cell secretome were found to be more efficient for the treatment of COVID-19 than MSCs (115). MSC-derived exosomes are harmless and exhibit similar effects as their parental cells in various models (including acute and chronic lung injury, sepsis, and ARDS models), therefore MSC-derived exosomes seem to be more valuable than the MSCs themselves to inhibit the COVID-19 inflammatory cascade $(116,117)$.

Exosomes act as vehicles that transfer specific cargo such as mRNA, non-coding RNAs, proteins, and DNA from parental cells to neighboring cells, and reprogram recipient cells due to their active molecular cargo; therefore, exosomes are regarded as "signalosomes" for controlling fundamental cellular functions $(118,119)$. Derkus et al. reported that exosomes can stimulate cellular regeneration and functional recovery under various pathological conditions. MSC-derived exosomes suppress fibrosis by preventing the differentiation of fibroblasts into myofibroblasts $(120,121)$. Both MSCs and MSC-derived exosomes are highly beneficial in clinical practice; however, they exhibit different beneficial effects. On one hand, a few studies have indicated that MSCs are more effective than MSCderived exosomes. For instance, Silva et al. demonstrated that MSCs are more effective than exosomes in reducing lung injury in ARDS (122). Although MSCs show efficacy in some contexts, MSCs still have some side effects including intravascular aggregation causing lung dysfunction that might synergize with the pneumonia and vascular clots associated with COVID-19, causing significant central or peripheral vascular insufficiency (22). On the other hand, other clinical studies suggest that MSCderived exosomes reduce the levels of pro-inflammatory cytokines and the repair of the damaged lung architecture. Altogether, these findings suggest that the MSC-secretome is a high-quality, safe, and effective therapeutic agent (113). During influenza virus infection, airway exosomes are released and stimulate the antiviral innate immune response (123). Using exosomes for severe COVID-19 cases involves the use of convalescent plasma containing trillions of exosomes that serve as immunomodulators. Abraham et al. reported that postexosomal infusion reduced the level of cytokine storm and pro-inflammatory signaling, which are primarily responsible 
for ARDS pathogenesis (124). Another study found that exosomes increase the level of anti-inflammatory signaling mediators that can reduce the severity of lung injury by increasing the permeability and function of the alveolar epithelium (116). Several pre-clinical and clinical studies have explored the potential utility of exosomes for treating COVID-19.

To date, various therapeutic strategies have been developed to overcome COVID-19 including antivirals, antibiotics, and biologics (eg, remdesivir, hydroxychloroquine, and tocilizumab), which have yielded mixed outcomes $(24,125-$ 127). Vaccination and convalescent plasma could be efficient therapeutics; however, their efficacy requires stable viral epitopes. The high rate of mutation of SARS-CoV-2 can directly suppress host $\mathrm{T}$ cell function, which renders therapies ineffective (25). Plasma therapy results in a positive response in severely ill patients and increases their survival rate (128). Targeting the SARS-CoV-2 S protein using neutralizing antibodies (nAbs) has also been proposed as a COVID-19 therapeutic (129, 130). Cytokine therapy, on the other hand, is able to inhibit viral replication $(131,132)$ For example, interferon- $\alpha 2 b$ treatment displayed a positive response in COVID-19 patients, resulting in a shortened duration of viral shedding and downregulation of markers of acute inflammation such as C-reactive protein and interleukin-6 (IL-6) (133). Another approach is targeting the SARS-CoV-2 viral RNA genome using small interfering RNAs (siRNAs) to target and neutralize SARS-CoV-2 RNA. siRNAs, RNA aptamers, and antisense oligonucleotides are effective alternative approaches for treating SARS. The same phenomenon can be applied to overcome pathological complications caused by SARS-CoV-2 $(134,135)$.

Due to the inherent features of exosomes such as high bioavailability, exceptional biocompatibility, and low immunogenicity, exosomes are promising drug delivery candidates for intercellular communication. These features have resulted in exosomes attracting therapeutic attention in recent years (136). A significant issue associated with COVID-19 treatment lies in early detection, which is imperative to help reduce COVID-19 patient mortality. In addition, the development of novel therapeutic strategies is essential. EVs play an important role as biomarkers for predicting disease progression in COVID-19 patients. Exosomes are double lipid bilayers containing various biomolecules involved in various physiological and pathological processes, including host immune responses. Recent studies suggest that exRNAs play a critical role in biomarker discovery and therapeutics (137). Therefore, the identification of exRNAs will be of great importance for COVID-19 therapeutics.

According to Databridgemarketresearch.com, the exosome therapeutic market is expected to gain market growth in the forecast period of 2019-2026, reaching 31,691.52 million USD by 2026. Therefore, exosome-based therapy for COVID-19 is a significant therapeutic focus. MSCs have been used to treat various types of diseases, including graft vs. host disease (138), type 2 diabetes (139) autoimmune diseases (140), and spinal cord injuries (141). Intravenous injection of HUMSCs suppressed the cytokine storm and significantly improved the outcomes of severe COVID-19 patients (107). Leng et al. showed promise for MSC therapy in saving the lives of COVID-19 patients with severe complications. MSC-derived exosomes showed promising results in severe COVID-19 patients who were already receiving hydroxychloroquine and azithromycin treatment (26). Exosome treatment resulted in $71 \%$ of the patients recovering from COVID-19. Bone marrow-derived exosomes, secreted by bmMSCs, are novel, multitargeted, next-generation biological agents, which represent a complex mix of signaling nanovesicles that can repress the cytokine storm and reverse the suppression of host antiviral defenses, characteristic of COVID-19 (27). Several animal models of acute lung injury, ARDS, asthma, and other inflammatory diseases have suggested that intravenously-injected bone marrow-derived exosomes reduced alveolar inflammation, enhanced edema clearance, restored leaky epithelial membranes, and affected other processes involved in cytokine storm (142-147). Exosomes loaded with a miRNA-155 mimic significantly increased miRNA-155 levels in primary mouse hepatocytes and the liver of miRNA-155 knockout mice. Significant reduction and prevention of LPS-induced TNF $\alpha$ production and SOCS1 mRNA levels was observed in treatment of RAW macrophages respectively (148).

MSC-derived exosome-delivered miR-21-5p protected lung epithelial cells against oxidative stress-induced cell death (149). The expression of alpha-1-antitrypsin on the surface of MSCderived exosomes serves as a potent inhibitor of neutrophilderived proteolytic enzymes and protects lung epithelial cells from anti-inflammatory and immunomodulatory effects (150). Animal studies have demonstrated that administration of MSCderived exosomes increased the proliferation of lung epithelial cells (151). Exosomes contain miRNAs such as miR-145 and proteins that promote lung tissue repair and regeneration (152). MSC-derived exosomes induce the expression of immunosuppressive cytokines such as IL-10 and TGF- $\beta$, and consequently modulate the phenotype and function of lunginfiltrating dendritic cells, which protects the lungs against detrimental macrophage- and DC-driven systemic immune responses and also involved to regulate cytokine storm caused by SARS-CoV-2 (Figure 4) (153). Systemic administration of MSC-derived exosomes reduced Escherichia coli endotoxininduced acute lung injury in a mouse model and restored alveolar fluid clearance (154). Intravenous injection of MSCderived exosomes significantly protected the brain against sepsisinduced injury in rats by decreasing the levels of TNF- $\alpha$, IL-1 $\beta$, $\mathrm{NF}-\kappa \mathrm{B}$, and matrix metallopeptidase 9 in the lungs. In addition, these exosomes decreased endothelial cell apoptosis and IL-6 production, and consequently increased IL-10 production (155).

COVID-19 patients were found to have exudative and proliferative phases of diffuse alveolar damage and microvessel thrombosis, which alters alveolar permeability and neutrophil infiltration $(148,156,157)$. An in vivo model of lung injury with severe E. coli pneumonia showed reduced neutrophil infiltration by the administration of MSC-derived EVs $(154,158)$. Further evidence from a pig model of influenza virus-induced lung injury showed that MSC-derived EVs have a promising level of antiviral 


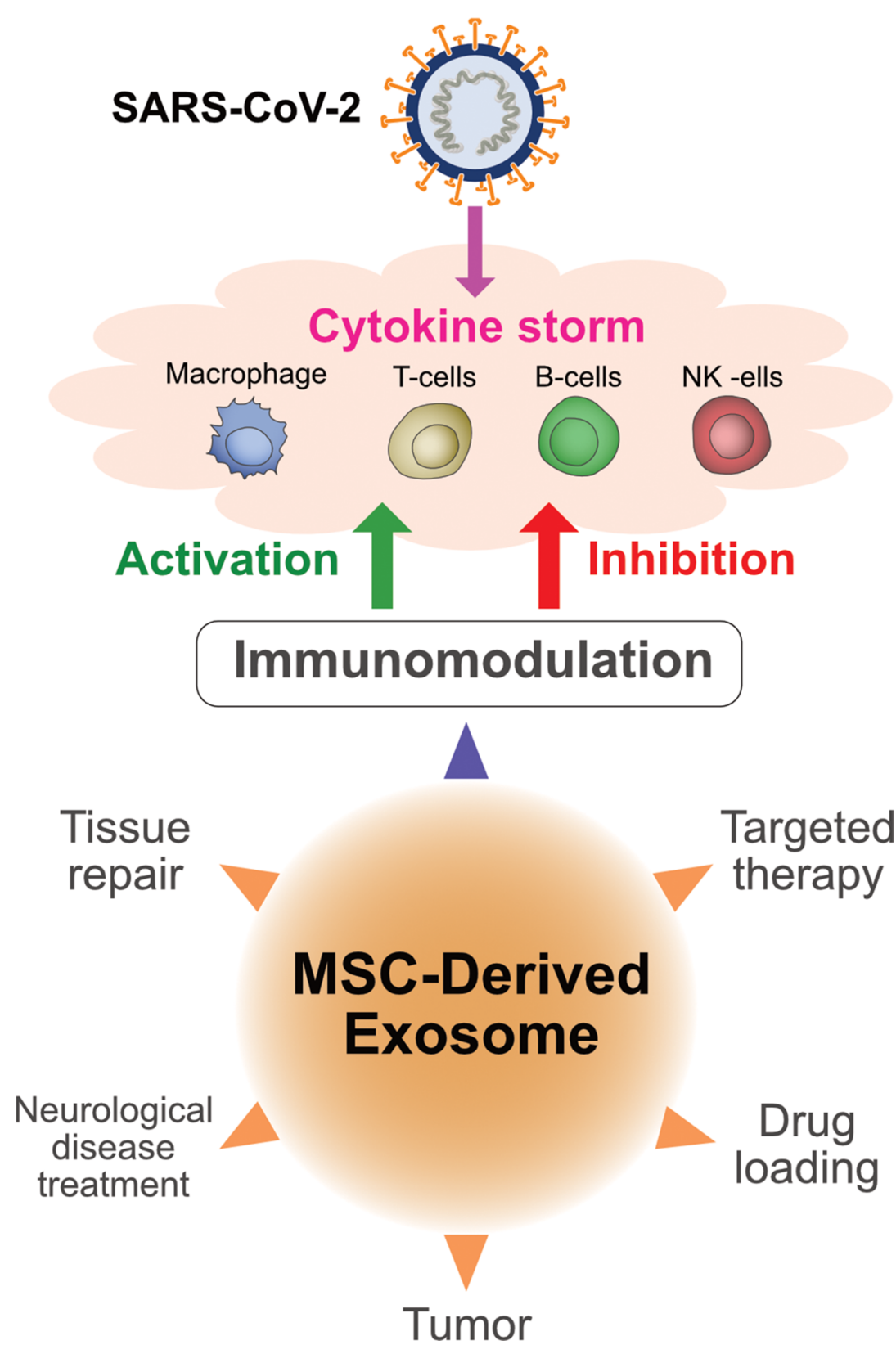

FIGURE 4 | Multifunctional aspects of exosomes derived from mesenchymal stem cells and immunomodulatory effects of exosomes on COVID-19.

activity and can suppress influenza virus replication after viral entry into lung epithelial cells in vitro, decreasing viral load (159).

Angiogenesis is a multistep process rising new capillaries and blood vessels from pre-existing blood vessels are essential for tumor growth and metastasis. Specifically, tumor cells and tumor cells derived exosomes are abundantly release exosomes containing different kinds of biomolecules such as angiogenic molecules that contribute to inducing angiogenesis (160). For example, exosome purified from primary human malignant mesothelioma (MM) can induce migration, vascular remodeling, and angiogenesis in a MM model (161). Proteomic analysis demonstrated that exosomes contain oncogenic cargo inducing cell migration and tube formation molecules (162) Exosomes derived from murine multiple myeloma induced metastatic niche in bone marrow and promote angiogenesis in vivo (163). Exosomes derived from Glioblastoma multiforme (GBM) contains rich mount of angiogenic proteins, which promoted angiogenesis in endothelial cells (164-166) Exosomes are derived from MSCs serving as key therapeutic effectors of MSCs to promote tissue regeneration (167). A review summarized about role of exosomes 
in convalescent plasma therapy for COVID-19, and that they could be of use for the treatment of COVID-19 Kawasaki's-like multisystem inflammatory syndrome and as drug delivery nanocarriers for antiviral therapy (168). Recently, stem cell secretome could offer a new therapeutic approach in treating COVID-19 fibrotic lungs through its anti-inflammatory and antifibrotic factors.

\section{USING PHARMACOLOGICAL INHIBITORS OF EXOSOME PATHWAY FOR COVID-19 TREATMENT}

Viruses use machinery similar to exosomes, therefore, the use of pharmacological exosome inhibitors could be a valuable therapeutic approach to counteract viral infections, including the current SARS-CoV-2 outbreak (53). For example, the EV inhibitor GW4869 suppresses ZIKV propagation by blocking neutral sphingomielinase-2 (169), and Dynasore inhibits endocytic and exocytic processes in EBV-infected cells (170). Based on the similarities between exosomes and SARS-CoV-2, pharmacological exosome inhibitors could represent effective COVID-19 therapeutics by inhibiting virus budding by blocking EV trafficking or inhibiting the release and spread of "viral" EVs. Exosome inhibitors are categorized as EV trafficking inhibitors and lipid metabolism inhibitors (53, 171). For example, calpeptin inhibits microvesicle production by activated platelets (172-174) in HEK293 cells (175) and PC3 cells (176), and inhibits SARS-CoV replication in vitro (177). Ras is a family of small GTPases involved in exosome release (178). Manumycin A treatment reduced the amount of CD63-bearing exosomes in F11 cells (179) and prostate cancer cells and during the wound healing process $(180,181)$. Cytoskeletal proteins such as the serine-threonine kinases ROCK1 and ROCK2 play an important role in vesicle budding. Y27632 is a competitive inhibitor of both ROCK1 and ROCK2 which decreases the production of exosomes in different endothelial cell lines (182186). Microvesicles are involved in lung inflammation; thus, reducing microvesicle biogenesis could protect against severe lung damage. Dai et al. demonstrated that Y27632 suppresses microvesicle production and alleviates lung inflammation (187). These findings demonstrate promise for pharmacological exosome inhibitor-based approaches in the treatment of COVID-19 (188). Verma et al. suggested that based on docking analysis, pantethine potentially binds to the substratebinding site and inhibits the main SARS-CoV-2 protease (185). Imipramine is an acid sphingomyelinase inhibitor that plays a vital role in ceramide formation and is involved in increasing membrane fluidity, exosome release, and microvesicle generation (189). SARS-CoV-2 uses macropinocytosis at multiple stages during its replication. Hence, imipramine can be used as a macropinocytosis inhibitor, and could be repurposed as a therapeutic agent for the treatment of COVID-19 (190). Similarly, GW4869 is a potent, specific non-competitive inhibitor of membrane neutral sphingomyelinase, which controls the production and release of vesicles. Therefore,
GW4869 is considered a potential therapeutic agent for COVID-19. Altogether, pharmacological inhibitors that inhibit exosome biogenesis are appropriate candidates for COVID-19.

\section{EXOSOMES AS DRUG DELIVERY VEHICLES FOR COVID-19}

Exosomes are considered to be an excellent vehicle for delivering a prospective drug to infected cells. Exosomes are dependable vesicles due to their tropism to different tissues, the ability to cross biological barriers, and their ability to protect the encapsulated material from the immune system and biological degradation (191). Exosomes have several advantages over synthetic delivery systems, as exosomes are natively present in body fluids and are stable under physiological $\mathrm{pH}$ or temperature, are less toxic and less immunogenic, and contain natural cargo (Figure 5). The most attractive feature of exosomes compared to synthetic delivery vesicles is that they can deliver cargo to specific recipient cells due to their structural properties (ie, membrane proteins and lipids) and they can cross the bloodbrain barrier (BBB) through endocytic mechanisms to deliver materials to the brain via the BBB $(5,192,193)$. miRNAs and various drugs can be encapsulated into exosomes. These miRNAs or drugs can target specific molecules inside the infected cells to reduce local inflammation or prevent apoptosis in lung cells (194). Song et al. reported that miR$146 \mathrm{a}$ is contained in MSC-derived exosomes, and pre-treatment of the MSCs with IL-1 $\beta$ augmented their immunomodulatory effects and led to targeting of specific cells, since their exosomes transferred miR-146a to the target cells (195).

Due to the specific structure of exosomes, they are suitable delivery agents and can accommodate multiple drugs which can be used in a variety of diseases (196). The immunomodulatory cargo of MSC-derived exosomes combined with antiviral drugs makes them a novel tool for COVID-19 treatment (197). All FDA-approved drugs for the treatment of COVID-19 can be loaded into exosomes. For example, remdesivir or antiviral drugs, which are prescribed for the treatment of patients with COVID-19, can be loaded into exosomes $(24,198)$. Dinh et al. reported that MSC-derived exosomes delivered via inhalation to COVID-19 patients (NCT04276987) significantly promoted lung repair in pulmonary fibrosis (199). Coronavirus infections increased the levels of circulating exosomes containing lungassociated self-antigens as well as viral antigens and the $20 \mathrm{~S}$ proteasome. A study by Gunasekaran et al. suggested that respiratory viral infected cells produce exosomes containing viral particles, and that these exosomes are involved in various processes related to SARS-CoV-2 infection and spread (86). Therefore, inhibition of exosome biogenesis and secretion from infected cells may reduce the speed and development of infection; however, therapeutic applications of exosomes in COVID-19 may comprise their use as a drug delivery system and utility as therapeutic agents for suppressing inflammatory responses and regeneration of damaged tissues. Exosomes act as signalosomes by transferring active cargo to the recipient cells, 


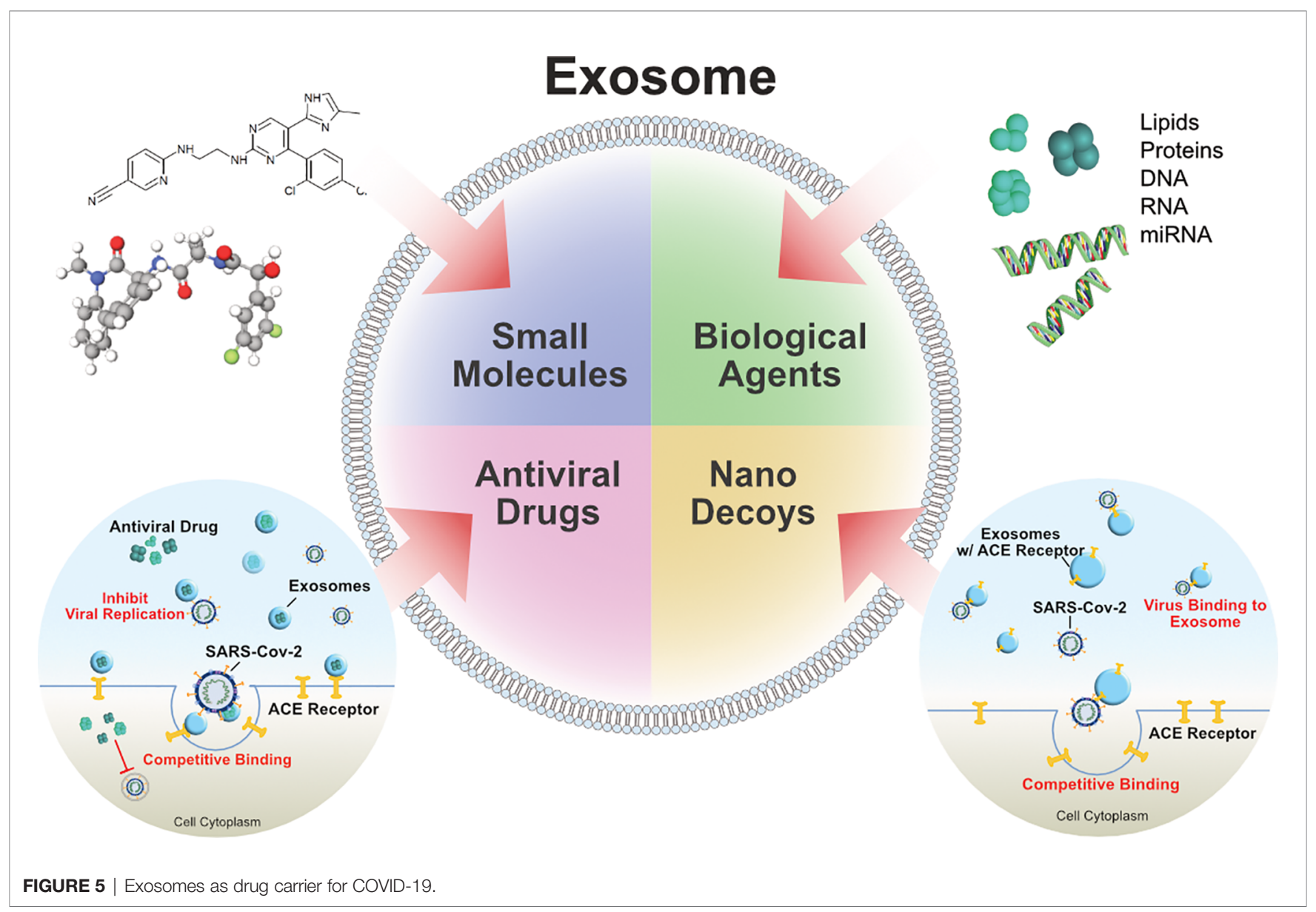

and they can reprogram recipient cell function $(118,119)$. However, further research and clinical trials are necessary to determine the safety, specificity, proficiency, and delivery mechanisms of drugs to target tissues. Heparin has antiviral properties and serves as localized drug delivery vehicle with exosomes and low-molecular weight heparin have been used in the anticoagulant management of COVID-19. Intrapulmonary delivery of heparin in COVID-19 patients exhibited clinical efficacy (200). Localized delivery of heparin act as antiinflammatory, cytoprotective and membrane stabilizing effects (200). The immunomodulatory cargo of MSCs exosomes combined with the anti-viral drugs makes them a novel intervention tool for the treatment of the disease (197). For example, exosomes can be used as drug delivery vehicle for Remdesivir for the treatment of patients with Covid-19 $(24,29)$.

\section{EXOSOMES AND VACCINES FOR COVID-19}

Presently, classical vaccines are developed using live-attenuated and inactivated viruses, with special emphasis on the viral $S$ protein and other strategies such as viral-vector-based vaccines, mRNA vaccines, or those with the full-length $S$ protein or its subunit (201-203). There are currently more than 50 COVID-19 vaccine candidates in clinical trials (www.who.int). The World Health Organization (WHO) is accelerating the process of vaccine development to help overcome the pandemic, and COVAX (led by WHO, GAVI, and CEPI) will facilitate the equitable access and distribution of these vaccines to protect people in all countries. Among the numerous vaccines, BNT162b2 (Pfizer, New York City, USA and BioNTech, Mainz, Germany) and mRNA-1273 (Moderna, Cambridge, MA, USA) vaccines have been approved by medical regulatory authorities in the UK, USA, and EU, and a mass vaccination campaign started in December. ChAdOx1 nCoV-19 (AstraZeneca, Cambridge, UK and Oxford University, UK) has been recently approved by UK authorities. In addition, some biotechnology companies are developing EV-based vaccines using exosomes. For example, Carpicor Therapeutics formulated a COVID-19 vaccine by loading mRNAs for the full-length $S$ protein and for modified S, N, M, and E proteins into EVs. Allele Biotechnology and Pharmaceuticals is developing an EV-based mRNA vaccine and CoVEVax vaccine by Ciloa, which consists of EVs containing the full $S$ protein. Codiak BioSciences and Versatope Therapeutics are also developing vaccines consisting of engineered EVs (203).

Exosomes play an important role in cell-to-cell communication and can induce a strong immune response due 
to the presence of antigens. Exosomes can be engineered to display viral antigens and induce high and specific CD8 (+) T cell and $\mathrm{B}$ cell reactions; therefore, these antigen-presenting exosomes represent a novel vaccine strategy. Generally, exosomes present a low basal immunogenic profile, and engineered exosomes will be a safe, dependable, flexible, and efficient strategy for virus-free vaccine design. The safety profile of exosomes is promising. In vitro studies confirmed that EVs released from human MSCs exhibited no genotoxic, hematological, or immunological effects (204). Intraperitoneal injection of human MSC-derived CD81+/CD9+/CD63+ EVs in immunocompetent mice showed no toxicity (205). Another mouse study performed transcriptomic analyses of HePG2 cells that received EVs derived from human embryonic kidney Expi293F cells and found that they did not exhibit hepatotoxicity or a proinflammatory cytokine response (206). Biotechnology companies are currently developing exosomebased vaccines against COVID-19 by displaying the SARSCoV-2 S protein on the exosome surface or delivery of mRNA corresponding to viral proteins through exosomes. Studies have demonstrated that EVs released from monocytes that are loaded with viral peptides from various viruses can trigger the release of interferon gamma (IFN- $\gamma$ ) from CD8 $(+) \mathrm{T}$ cells in an antigenspecific manner (207). IFN- $\boldsymbol{\gamma}$ is a well-known marker of the cellular immune response; hence, such exosomes could represent an effective system for vaccine design. Kuate et al. reported that EV-based vaccines induced higher specific antibody titers than those present in serum from patients with SARS. Thus, similar EV-based vaccines could be applied to COVID-19 treatment (208). Study reported that exosomes containing the SARS S protein induced neutralizing antibody titers that were promoted by priming with the SARS coronavirus spike vaccine and then increased with the adenoviral vector vaccine (208). For the development of a vaccine against SARS, the $S$ protein has been incorporated into exosomes to produce a chimeric protein (208). Exosomes derived from virus-infected cells promote viral infection and suppress immune cell responses (209).

\section{ROLE OF EXOSOMAL PROTEIN IN HOST RESPONSE TO SARS-COV-2}

Dexosomes are nothing but exosomes released by dendritic cells (DCs), which are symmetric nanoscale heat-stable vesicles that consist of a lipid bilayer displaying a characteristic series of lipid and protein molecules. Dexosomes contribute to antigen-specific cellular immune responses by incorporating the MHC proteins with antigen molecules and transferring the antigen-MHC complexes and other associated molecules to naïve DCs. Dexosomes can be used as therapeutic antitumor vaccines in malignant melanoma and non-small cell lung carcinoma patients (210). Exosomes play significant role in human retroviral infections by transfer viral components such as miRNAs and proteins that promote infection and inflammation (211). Dexosomes are under intense scrutiny in clinical trials for various inflammatory diseases. Dexosomes are function as immunomodulatory, immunotherapy for inflammatory bone disease. Recently, Elashiry et al. (212) showed a key role for encapsulated TGFb1 in promoting a bone sparing immune response through analysis of by high throughput proteomics, with non-therapeutic exosomes from immature DCs and mature DCs as controls. Authors identified predominant expression of immunoregulatory proteins as well as proteins involved in trafficking from the circulation to peripheral tissues, cell surface binding, and transmigration. Expression of immunoregulatory functions and unique proteins of dexosomes were ability to regulate expression of the SARSCOV-2 receptor, ACE2 (213-215).

\section{ROLE, MECHANISM AND MANAGEMENT OF EXOSOMES IN TREATMENT OF SARS-COV-2 INFECTED PATIENTS}

SARS-CoV-2 infection causes cytokine storm and overshoot immunity in humans; Exosomes from COVID-19 patients contains an elevated level of TNC and FGB in exosomes from plasma of COVID-19 patients, and enhance expression of proinflammatory cytokines TNF- $\alpha$, IL-6, and chemokine CCL5 through the NF- $\kappa \mathrm{B}$ signaling pathway upon exposure to hepatocytes. Plasma exosomes from COVID-19 infected patients contains high level of tenascin-C (TNC) and fibrinogen- $\beta$ (FGB) compared to that of healthy normal controls. Both TNC and FGB stimulate pro-inflammatory cytokines via NF- $\mathrm{KB}$ pathway (216). Exosomes contains noncoding RNAs play a crucial role in virus mediated disease progression. The presence of TNC and FGB in SARS-CoV-2 infected patient exosomes may be a mechanism for cytokine storm resulting in micro-thrombosis in some patients and TNC and/or FGB can be used as the potential prognostic markers for COVID-19 patients. TNC and FGB-enriched exosomes from COVID-19 plasma and may be correlated for the first time with pathogenesis (216) Fujita et al. reported that antiviral responserelated EV proteins, coagulation-related markers, and liver damage-related exRNAs serving as potential early predictive biomarkers for COVID-19 severity (217). To reveal the mechanism of various type of viral diseases such as (SARSCoV-1), SARS-CoV-2, and Middle East respiratory syndrome coronavirus (MERS-CoV), a comparative hostcoronavirus protein interaction networks was analyzed and assessed the cellular localization of each viral protein across the three strains. Authors conducted two genetic screens of SARSCoV-2 interactors to prioritize functionally-relevant host factors and structurally characterized one virus-host interaction (218). EVs are playing significant role in spread and viral infection through delivering biomolecules to the recipient cells. Therefore it is necessary to develop technologies for exosome biogenesis and uptake, exosome-therapy, exosome-based drug delivery system, and exosome- based vaccine (217). Several studies are documented that EVs can reduce the inflammatory response in the lung, regenerate and repair the damaged alveolar epithelium and endothelium, and prevent pulmonary fibrosis. The release of 
their cargoes, and miRNAs seem to play a role in the EV mechanism of action.

\section{CLINICAL TRANSLATION PATHWAY OF EXOSOMES}

Exosomes are playing potential roles in the treatment of various type of diseases including cancer, cardiovascular, neurodegenerative, tissue injury and pathogenic infections particularly COVID-19 (219). Exosomes are nanovesicles derived from mesenchymal stem/stromal cells exhibited many beneficial effects in various models of disease. To date, more than 200 preclinical studies of exosome-based therapies in a number of different animal models MSCs and exosome-enriched fractions (MEX) possess anti-inflammatory properties in both preclinical and clinical studies. Therefore, MEX considered to be a therapeutic platform technology (220). Cargoes are released upon fusion of exosomes fuse with the plasma membrane while direct interaction of exosomes with the surface receptors of recipient cells induces downstream signalling cascades (221, 222). Post internalization of exosomes follows endocytic pathway. Exosomes are also able to use pathways similar to viruses to avoid lysosomal degradation. MSC-derived exosomes human bone-marrow (hBM) and human umbilical cord perivascular cells (hUCPVCs) exhibited effect on neurological tissues, blood-brain barrier stability in lipopolysaccharideinduced neuroinflammation (223-225). Exosomes derived from chimeric antigen receptor (CAR) $\mathrm{T}$ cells shows potential safer therapies $(226,227)$. Exosomes derived from the more antigen-specific subtype CD8 $+\mathrm{T}$ cell show antiviral activity by inhibiting viral transcription through the presence of antiviral membrane-bound factors (228). Exosomes are derived from adipose-derived stem cells (ADSCs) shows immune responses by increasing $\mathrm{T}$ cell regulator leading to the increase of antiinflammatory IL-4 and IL-10 levels associated to the decrease of the proinflammatory cytokine levels IL-17 and IFN $(229,230)$. Intravenous administration of clinical-grade ACE2 mesenchymal stem cells shows improvement in pulmonary associated illness of COVID-19 patients by significant decrease level of serum pro-inflammatory cytokine TNF- $\alpha$ (131). Recently, a review summarized potential beneficial effects of exosomes on COVID-19 (231). Particularly, Inhalation of MSC derived exosomes exhibited considerable improvement COVID19. MSC transplantation reduces the severity of influenza virusinduced lung injuries and lowers mortality, suggesting a potential role for MSCs and MSC EVs in COVID-19 treatment (128). Hence, exosomes mediated therapy is alternative, feasible and effective therapy for covid-19 patients.

\section{CONCLUSIONS AND FUTURE PERSPECTIVES}

Exosomes are nano-sized vesicles secreted by all cell types. Due to their diverse properties, exosomes can be engineered to be used as various types of antiviral therapeutics, and can be useful in treating COVID-19. Exosome secretion is either systemic or localized. Exosomes play an important role as signalosomes in the pathogenesis and progression of various diseases, including viral diseases. Exosome activities can either lead to an aggravation of disease or beneficial effects, depending on the cargo they carry. In the case of SARS-CoV-2, exosomes could contribute to promoting spread and infection due to the presence of CD9 and ACE2, which are involved in promoting SARS-CoV-2 infection. Thus, exosome-mediated treatment, such as stem cell-derived exosome therapy, exosome-based drug delivery, inhibition of exosome biogenesis and uptake, and exosomebased vaccines could be effective for COVID-19 treatment. Recently, exosomes have received significant attention in both academia and industry due to their beneficial effects, and are now being used as biomarkers, immunomodulators, therapeutics, and vaccines. For example, exosomes derived from bmMSCs reduced the cytokine storm in COVID-19 patients. The current SARSCoV-2 pandemic has jump-started research into exosome-based therapeutics. In this review, we discussed multifarious effects of exosomes, including the involvement of exosomes in COVID-19related virus transmission, infection, diagnosis, treatment, therapeutics, drug delivery, and vaccines. Exosome therapeutics are still associated with many limitations in relation to their production, purification, downstream processing, and application. Future research is required to optimize the process of exosome isolation to produce high yields and to determine the best therapeutic properties for use in COVID-19 treatment. Future studies should focus on well-designed large-scale randomized controlled trials comparing the therapeutic effects of exosomes derived from different sources to provide important insights into therapeutic development. The heterogeneity of exosomes resulting from differences in source, aging, isolation, purification, and function as a result of originating from different laboratories may lead to differences in their immunomodulatory activities, regenerative activities, and effects on viral infections. Hence, basic research focusing on improving the isolation, characterization, purification, and application of exosomes will be fundamental to determine their benefits and safety as future therapies to treat COVID-19. In particular, scientists in academia and industry should collaborate to develop an optimal way to scale-up production to generate functional exosomes according to current good manufacturing practice standards. Another important consideration is decorating exosomes with ACE-2 to compete with the SARS-CoV-2 S protein. Exosomes should be loaded with a molecule(s) of choice to interrupt the activities of the virus in the cell and protect the airways and lungs. Further research is essential to fully elucidate the mechanisms of immunomodulation and the exosome cargo responsible for these cellular alterations that are specific to each clinical condition. Profiling of exosome cargo using proteomics, lipidomics, and RNA sequencing is crucial to address the current knowledge gap. Pre-clinical and clinical studies should examine the use of exosomes for treating immunological disorders. Finally, the use of exosomes derived from various sources in the treatment of COVID-19 pneumonia and lung 
pathology should be investigated and assessed for viability and safety. As exosomes are associated with numerous beneficial effects, in order to exploit the full potential of exosomes for human health, further studies are required to resolve issues associated with cell-based therapies and to clarify the safety and effectiveness of these therapies and their long-term outcomes.

\section{AUTHOR CONTRIBUTIONS}

All authors listed have made a substantial, direct, and intellectual contribution to the work and approved it for publication.

\section{REFERENCES}

1. Cascella M, Rajnik M, Aleem A, Dulebohn SC, Di Napoli R. Features, Evaluation, and Treatment of Coronavirus (COVID-19). Statpearls. Treasure Island, FL: StatPearls Publishing (2021).

2. Mousavizadeh L, Ghasemi S. Genotype and Phenotype of COVID-19: Their Roles in Pathogenesis. J Microbiol Immunol Infect (2020) 54(2):159-63. doi: 10.1016/j.jmii.2020.03.022

3. Hoffmann M, Kleine-Weber H, Schroeder S, Krüger N, Herrler T, Erichsen S, et al. SARS-CoV-2 Cell Entry Depends on ACE2 and TMPRSS2 and is Blocked by a Clinically Proven Protease Inhibitor. Cell (2020) 181:27180.e8. doi: 10.1016/j.cell.2020.02.052

4. Pocsfalvi G, Mammadova R, Ramos Juarez AP, Bokka R, Trepiccione F, Capasso G. Covid-19 and Extracellular Vesicles: An Intriguing Interplay. Kidney Blood Press Res (2020) 45:661-70. doi: 10.1159/000511402

5. Théry C, Witwer KW, Aikawa E, Alcaraz MJ, Anderson JD, Andriantsitohaina R, et al. Minimal Information for Studies of Extracellular Vesicles 2018 (MISEV2018): A Position Statement of the International Society for Extracellular Vesicles and Update of the MISEV2014 Guidelines. J Extracell Vesicles (2018) 7:1535750. doi: 10.1080/20013078.2018.1535750

6. Raposo G, Stoorvogel W. Extracellular Vesicles: Exosomes, Microvesicles, and Friends. J Cell Biol (2013) 200:373-83. doi: 10.1083/jcb.201211138

7. Kowal J, Tkach M, Théry C. Biogenesis and Secretion of Exosomes. Curr Opin Cell Biol (2014) 29:116-25. doi: 10.1016/j.ceb.2014.05.004

8. Statello L, Maugeri M, Garre E, Nawaz M, Wahlgren J, Papadimitriou A, et al. Identification of RNA-Binding Proteins in Exosomes Capable of Interacting With Different Types of RNA: RBP-Facilitated Transport of RNAs Into Exosomes. PloS One (2018) 13:e0195969. doi: 10.1371/ journal.pone.0195969

9. zPan BT, Teng K, Wu C, Adam M, Johnstone RM. Electron Microscopic Evidence for Externalization of the Transferrin Receptor in Vesicular Form in Sheep Reticulocytes. J Cell Biol (1985) 101:942-8. doi: 10.1083/jcb.101.3.942

10. Ratajczak J, Miekus K, Kucia M, Zhang J, Reca R, Dvorak P, et al. Embryonic Stem Cell-Derived Microvesicles Reprogram Hematopoietic Progenitors: Evidence for Horizontal Transfer of mRNA and Protein Delivery. Leukemia (2006) 20:847-56. doi: 10.1038/sj.leu.2404132

11. Zhang J, Li S, Li L, Li M, Guo C, Yao J, et al. Exosome and Exosomal microRNA: Trafficking, Sorting, and Function. Genomics Proteomics Bioinf (2015) 13:17-24. doi: 10.1016/j.gpb.2015.02.001

12. Record M, Carayon K, Poirot M, Silvente-Poirot S. Exosomes as New Vesicular Lipid Transporters Involved in Cell-Cell Communication and Various Pathophysiologies. Biochim Biophys Acta (2014) 1841:108-20. doi: 10.1016/j.bbalip.2013.10.004

13. Choi DS, Kim DK, Kim YK, Gho YS. Proteomics, Transcriptomics and Lipidomics of Exosomes and Ectosomes. Proteomics (2013) 13:1554-71. doi: 10.1002/pmic.201200329

14. Yuana Y, Sturk A, Nieuwland R. Extracellular Vesicles in Physiological and Pathological Conditions. Blood Rev (2013) 27:31-9. doi: 10.1016/ j.blre.2012.12.002

\section{FUNDING}

This work was supported by a grant from the Science Research Center (2015R1A5A1009701) of the National Research Foundation of Korea.

\section{ACKNOWLEDGMENTS}

This study was supported by the KU-Research Professor Program of Konkuk University.

15. Fleming A, Sampey G, Chung MC, Bailey C, van Hoek ML, Kashanchi F, et al. The Carrying Pigeons of the Cell: Exosomes and Their Role in Infectious Diseases Caused by Human Pathogens. Pathog Dis (2014) 71:109-20. doi: 10.1111/2049-632x.12135

16. van Dongen HM, Masoumi N, Witwer KW, Pegtel DM. Extracellular Vesicles Exploit Viral Entry Routes for Cargo Delivery. Microbiol Mol Biol $\operatorname{Rev}$ (2016) 80:369-86. doi: 10.1128/mmbr.00063-15

17. Lässer C, O’Neil SE, Shelke GV, Sihlbom C, Hansson SF, Gho YS, et al Exosomes in the Nose Induce Immune Cell Trafficking and Harbour an Altered Protein Cargo in Chronic Airway Inflammation. J Transl Med (2016) 14:181. doi: 10.1186/s12967-016-0927-4

18. Martinez-Bravo MJ, Wahlund CJ, Qazi KR, Moulder R, Lukic A, Rådmark O, et al. Pulmonary Sarcoidosis is Associated With Exosomal Vitamin DBinding Protein and Inflammatory Molecules. J Allergy Clin Immunol (2017) 139:1186-94. doi: 10.1016/j.jaci.2016.05.051

19. Lanyu Z, Feilong H. Emerging Role of Extracellular Vesicles in Lung Injury and Inflammation. BioMed Pharmacother (2019) 113:108748. doi: 10.1016/ j.biopha.2019.108748

20. Valadi H, Ekström K, Bossios A, Sjöstrand M, Lee JJ, Lötvall JO. ExosomeMediated Transfer of mRNAs and microRNAs is a Novel Mechanism of Genetic Exchange Between Cells. Nat Cell Biol (2007) 9:654-9. doi: 10.1038/ ncb1596

21. Schorey JS, Cheng Y, Singh PP, Smith VL. Exosomes and Other Extracellular Vesicles in Host-Pathogen Interactions. EMBO Rep (2015) 16:24-43. doi: 10.15252/embr.201439363

22. Askenase PW. Covid-19 Therapy With Mesenchymal Stromal Cells (MSC) and Convalescent Plasma Must Consider Exosome Involvement: Do the Exosomes in Convalescent Plasma Antagonize the Weak Immune Antibodies? J Extracell Vesicles (2020) 10:e12004. doi: 10.1002/jev2.12004

23. Polak K, Greze N, Lachat M, Merle D, Chiumento S, Bertrand-Gaday C, et al. Extracellular Vesicle-Based Vaccine Platform Displaying Native Viral Envelope Proteins Elicits a Robust Anti-SARS-CoV-2 Response in Mice. bioRxiv (2020). doi: 10.1101/2020.10.28.357137

24. Grein J, Ohmagari N, Shin D, Diaz G, Asperges E, Castagna A, et al. Compassionate Use of Remdesivir for Patients With Severe Covid-19. N Engl J Med (2020) 382:2327-36. doi: 10.1056/NEJMoa2007016

25. Wang X, Xu W, Hu G, Xia S, Sun Z, Liu Z, et al. Retracted ARTICLE: SARSCoV-2 Infects $\mathrm{T}$ Lymphocytes Through its Spike Protein-Mediated Membrane Fusion. Cell Mol Immunol (2020) 1-3. doi: 10.1038/s41423020-0424-9

26. Sengupta V, Sengupta S, Lazo A, Woods P, Nolan A, Bremer N. Exosomes Derived From Bone Marrow Mesenchymal Stem Cells as Treatment for Severe COVID-19. Stem Cells Dev (2020) 29:747-54. doi: 10.1089/ scd.2020.0080

27. Yang X, Yu Y, Xu J, Shu H, Xia J, Liu H, et al. Clinical Course and Outcomes of Critically Ill Patients With SARS-CoV-2 Pneumonia in Wuhan, China: A Single-Centered, Retrospective, Observational Study. Lancet Respir Med (2020) 8:475-81. doi: 10.1016/s2213-2600(20)30079-5

28. Gorbalenya AE, Baker SC, Baric RS, de Groot RJ, Drosten C, Gulyaeva AA, et al. Severe Acute Respiratory Syndrome-Related Coronavirus: The Species 
and Its Viruses - a Statement of the Coronavirus Study Group. bioRxiv (2020). doi: 10.1101/2020.02.07.937862. 2020.02.07.937862.

29. Zhou P, Yang XL, Wang XG, Hu B, Zhang L, Zhang W, et al. A Pneumonia Outbreak Associated With a New Coronavirus of Probable Bat Origin. Nature (2020) 579:270-3. doi: 10.1038/s41586-020-2012-7

30. Lu R, Zhao X, Li J, Niu P, Yang B, Wu H, et al. Genomic Characterisation and Epidemiology of 2019 Novel Coronavirus: Implications for Virus Origins and Receptor Binding. Lancet (2020) 395:565-74. doi: 10.1016/ s0140-6736(20)30251-8

31. Qian Z, Travanty EA, Oko L, Edeen K, Berglund A, Wang J, et al. Innate Immune Response of Human Alveolar Type II Cells Infected With Severe Acute Respiratory Syndrome-Coronavirus. Am J Respir Cell Mol Biol (2013) 48:742-8. doi: 10.1165/rcmb.2012-0339OC

32. Farkash EA, Wilson AM, Jentzen JM. Ultrastructural Evidence for Direct Renal Infection With SARS-CoV-2. J Am Soc Nephrol (2020) 31:1683-7. doi: 10.1681/asn.2020040432

33. Su H, Yang M, Wan C, Yi LX, Tang F, Zhu HY, et al. Renal Histopathological Analysis of 26 Postmortem Findings of Patients With COVID-19 in China. Kidney Int (2020) 98:219-27. doi: 10.1016/j.kint.2020.04.003

34. Wang W, Xu Y, Gao R, Lu R, Han K, Wu G, et al. Detection of SARS-CoV-2 in Different Types of Clinical Specimens. JAMA (2020) 323:1843-4. doi: $10.1001 /$ jama.2020.3786

35. Ling Y, Xu SB, Lin YX, Tian D, Zhu ZQ, Dai FH, et al. Persistence and Clearance of Viral RNA in 2019 Novel Coronavirus Disease Rehabilitation Patients. Chin Med J (Engl) (2020) 133:1039-43. doi: 10.1097/ $\mathrm{cm} 9.0000000000000774$

36. Monteil V, Kwon H, Prado P, Hagelkrüys A, Wimmer RA, Stahl M, et al. Inhibition of SARS-CoV-2 Infections in Engineered Human Tissues Using Clinical-Grade Soluble Human ACE2. Cell (2020) 181:905-13.e7. doi: 10.1016/j.cell.2020.04.004

37. Knoops K, Kikkert M, Worm SH, Zevenhoven-Dobbe JC, van der Meer Y, Koster AJ, et al. SARS-Coronavirus Replication is Supported by a Reticulovesicular Network of Modified Endoplasmic Reticulum. PloS Biol (2008) 6:e226. doi: 10.1371/journal.pbio.0060226

38. Varga Z, Flammer AJ, Steiger P, Haberecker M, Andermatt R, Zinkernagel AS, et al. Endothelial Cell Infection and Endotheliitis in COVID-19. Lancet (2020) 395:1417-8. doi: 10.1016/s0140-6736(20)30937-5

39. Mönkemüller K, Fry L, Rickes S. Covid-19, Coronavirus, SARS-CoV-2 and the Small Bowel. Rev Esp Enferm Dig (2020) 112:383-8. doi: 10.17235/ reed.2020.7137/2020

40. Ziegler CGK, Allon SJ, Nyquist SK, Mbano IM, Miao VN, Tzouanas CN, et al. SARS-CoV-2 Receptor ACE2 Is an Interferon-Stimulated Gene in Human Airway Epithelial Cells and Is Detected in Specific Cell Subsets Across Tissues. Cell (2020) 181:1016-35.e19. doi: 10.1016/j.cell.2020.04.035

41. Smith JC, Sausville EL, Girish V, Yuan ML, Vasudevan A, John KM, et al. Cigarette Smoke Exposure and Inflammatory Signaling Increase the Expression of the SARS-CoV-2 Receptor ACE2 in the Respiratory Tract. Dev Cell (2020) 53:514-29.e3. doi: 10.1016/j.devcel.2020.05.012

42. Wrapp D, Wang N, Corbett KS, Goldsmith JA, Hsieh CL, Abiona O, et al. Cryo-EM Structure of the 2019-Ncov Spike in the Prefusion Conformation. Science (2020) 367:1260-3. doi: 10.1126/science.abb2507

43. Yan R, Zhang Y, Li Y, Xia L, Guo Y, Zhou Q. Structural Basis for the Recognition of SARS-CoV-2 by Full-Length Human ACE2. Science (2020) 367:1444-8. doi: 10.1126/science.abb2762

44. Zhao Y, Zhao Z, Wang Y, Zhou Y, Ma Y, Zuo W. Single-Cell RNA Expression Profiling of ACE2, the Receptor of SARS-CoV-2. Am J Respir Crit Care Med (2020) 202:756-9. doi: 10.1164/rccm.202001-0179LE

45. Shang J, Wan Y, Luo C, Ye G, Geng Q, Auerbach A, et al. Cell Entry Mechanisms of SARS-CoV-2. Proc Natl Acad Sci USA (2020) 117:11727-34. doi: 10.1073/pnas.2003138117

46. Yu IT, Li Y, Wong TW, Tam W, Chan AT, Lee JH, et al. Evidence of Airborne Transmission of the Severe Acute Respiratory Syndrome Virus. $N$ Engl J Med (2004) 350:1731-9. doi: 10.1056/NEJMoa032867

47. Li Y, Huang X, Yu IT, Wong TW, Qian H. Role of Air Distribution in SARS Transmission During the Largest Nosocomial Outbreak in Hong Kong. Indoor Air (2005) 15:83-95. doi: 10.1111/j.1600-0668.2004.00317.x

48. Otter JA, Donskey C, Yezli S, Douthwaite S, Goldenberg SD, Weber DJ. Transmission of SARS and MERS Coronaviruses and Influenza Virus in
Healthcare Settings: The Possible Role of Dry Surface Contamination. J Hosp Infect (2016) 92:235-50. doi: 10.1016/j.jhin.2015.08.027

49. Huang C, Wang Y, Li X, Ren L, Zhao J, Hu Y, et al. Clinical Features of Patients Infected With 2019 Novel Coronavirus in Wuhan, China. Lancet (2020) 395:497-506. doi: 10.1016/s0140-6736(20)30183-5

50. Wang D, Hu B, Hu C, Zhu F, Liu X, Zhang J, et al. Clinical Characteristics of 138 Hospitalized Patients With 2019 Novel Coronavirus-Infected Pneumonia in Wuhan, China. JAMA (2020) 323:1061-9. doi: 10.1001/ jama.2020.1585

51. Li Q, Guan X, Wu P, Wang X, Zhou L, Tong Y, et al. Early Transmission Dynamics in Wuhan, China, of Novel Coronavirus-Infected Pneumonia. N Engl J Med (2020) 382:1199-207. doi: 10.1056/NEJMoa2001316

52. Chan JF, Yuan S, Kok KH, To KK, Chu H, Yang J, et al. A Familial Cluster of Pneumonia Associated With the 2019 Novel Coronavirus Indicating PersonTo-Person Transmission: A Study of a Family Cluster. Lancet (2020) 395:514-23. doi: 10.1016/s0140-6736(20)30154-9

53. Urciuoli E, Peruzzi B. Inhibiting Extracellular Vesicle Trafficking as Antiviral Approach to Corona Virus Disease 2019 Infection. Front Pharmacol (2020) 11:580505. doi: 10.3389/fphar.2020.580505

54. Hassanpour M, Rezaie J, Nouri M, Panahi Y. The Role of Extracellular Vesicles in COVID-19 Virus Infection. Infect Genet Evol (2020) 85:104422. doi: 10.1016/j.meegid.2020.104422

55. Hussein HA, Walker LR, Abdel-Raouf UM, Desouky SA, Montasser AK, Akula SM. Beyond RGD: Virus Interactions With Integrins. Arch Virol (2015) 160:2669-81. doi: 10.1007/s00705-015-2579-8

56. Sigrist CJ, Bridge A, Le Mercier P. A Potential Role for Integrins in Host Cell Entry by SARS-CoV-2. Antiviral Res (2020) 177:104759. doi: 10.1016/ j.antiviral.2020.104759

57. Théry C, Regnault A, Garin J, Wolfers J, Zitvogel L, Ricciardi-Castagnoli P, et al. Molecular Characterization of Dendritic Cell-Derived Exosomes. Selective Accumulation of the Heat Shock Protein Hsc73. J Cell Biol (1999) 147:599-610. doi: 10.1083/jcb.147.3.599

58. Clayton A, Turkes A, Dewitt S, Steadman R, Mason MD, Hallett MB. Adhesion and Signaling by B Cell-Derived Exosomes: The Role of Integrins. FASEB J (2004) 18:977-9. doi: 10.1096/fj.03-1094fje

59. Mathivanan S, Fahner CJ, Reid GE, Simpson RJ. ExoCarta 2012: Database of Exosomal Proteins, RNA and Lipids. Nucleic Acids Res (2012) 40:D1241-4. doi: $10.1093 /$ nar/gkr828

60. Kim DK, Kang B, Kim OY, Choi DS, Lee J, Kim SR, et al. Evpedia: An Integrated Database of High-Throughput Data for Systemic Analyses of Extracellular Vesicles. J Extracell Vesicles (2013) 2:10.3402/jev.v2i0.20384. doi: $10.3402 /$ jev.v2i 0.20384

61. Kim DK, Lee J, Kim SR, Choi DS, Yoon YJ, Kim JH, et al. Evpedia: A Community Web Portal for Extracellular Vesicles Research. Bioinformatics (2015) 31:933-9. doi: 10.1093/bioinformatics/btu741

62. Earnest JT, Hantak MP, Park JE, Gallagher T. Coronavirus and Influenza Virus Proteolytic Priming Takes Place in Tetraspanin-Enriched Membrane Microdomains. J Virol (2015) 89:6093-104. doi: 10.1128/jvi.00543-15

63. Gurunathan S, Chapman-Shimshoni D, Trajkovic S, Gerst JE. Yeast Exocytic V-SNAREs Confer Endocytosis. Mol Biol Cell (2000) 11:3629-43. doi: 10.1091/mbc.11.10.3629

64. Gurunathan S, David D, Gerst JE. Dynamin and Clathrin are Required for the Biogenesis of a Distinct Class of Secretory Vesicles in Yeast. EMBO J (2002) 21:602-14. doi: 10.1093/emboj/21.4.602

65. Earnest JT, Hantak MP, Li K, McCray PBJr., Perlman S, Gallagher T. The Tetraspanin CD9 Facilitates MERS-Coronavirus Entry by Scaffolding Host Cell Receptors and Proteases. PloS Pathog (2017) 13:e1006546. doi: 10.1371/ journal.ppat.1006546

66. Miyanishi M, Tada K, Koike M, Uchiyama Y, Kitamura T, Nagata S. Identification of Tim4 as a Phosphatidylserine Receptor. Nature (2007) 450:435-9. doi: 10.1038/nature06307

67. Feng D, Zhao WL, Ye YY, Bai XC, Liu RQ, Chang LF, et al. Cellular Internalization of Exosomes Occurs Through Phagocytosis. Traffic (2010) 11:675-87. doi: 10.1111/j.1600-0854.2010.01041.x

68. Wang J, Chen S, Bihl J. Exosome-Mediated Transfer of ACE2 (AngiotensinConverting Enzyme 2) From Endothelial Progenitor Cells Promotes Survival and Function of Endothelial Cell. Oxid Med Cell Longev (2020) 2020:4213541. doi: 10.1155/2020/4213541 
69. Badierah RA, Uversky VN, Redwan EM. Dancing With Trojan Horses: An Interplay Between the Extracellular Vesicles and Viruses. J Biomol Struct Dyn (2020) 1-27. doi: 10.1080/07391102.2020.1756409

70. Kwon Y, Nukala SB, Srivastava S, Miyamoto H, Ismail NI, Rehman J, et al. Detection of Viral RNA Fragments in Human iPSC-Cardiomyocytes Following Treatment With Extracellular Vesicles From SARS-CoV-2 Coding-Sequence-Overexpressing Lung Epithelial Cells. bioRxiv (2020). doi: $10.1101 / 2020.05 .14 .093583$

71. El-Shennawy L, Hoffmann AD, Dashzeveg NK, Mehl PJ, Yu Z, Tokars VL, et al. Circulating ACE2-Expressing Exosomes Block SARS-CoV-2 Infection as an Innate Antiviral Mechanism. bioRxiv (2020). doi: 10.1101/ 2020.12.03.407031. 2020.12.03.407031.

72. Gould SJ, Raposo G. As We Wait: Coping With an Imperfect Nomenclature for Extracellular Vesicles. J Extracell Vesicles (2013) 2. doi: 10.3402/ jev.v2i0.20389

73. Giannessi F, Aiello A, Franchi F, Percario ZA, Affabris E. The Role of Extracellular Vesicles as Allies of HIV, HCV and SARS Viruses. Viruses (2020) 12. doi: 10.3390/v12050571

74. Schorey JS, Harding CV. Extracellular Vesicles and Infectious Diseases: New Complexity to an Old Story. J Clin Invest (2016) 126:1181-9. doi: 10.1172/ jci81132

75. Martins ST, Alves LR. Extracellular Vesicles in Viral Infections: Two Sides of the Same Coin? Front Cell Infect Microbiol (2020) 10:593170. doi: 10.3389/ fcimb. 2020.593170

76. Mason RJ. Pathogenesis of COVID-19 From a Cell Biology Perspective. Eur Respir J (2020) 55. doi: 10.1183/13993003.00607-2020

77. Millet JK, Jaimes JA, Whittaker GR. Molecular Diversity of Coronavirus Host Cell Entry Receptors. FEMS Microbiol Rev (2020). doi: 10.1093/femsre/ fuaa057

78. Taguchi F, Matsuyama S. [Cell Entry Mechanisms of Coronaviruses]. Uirusu (2009) 59:215-22. doi: 10.2222/jsv.59.215

79. Li W, Moore MJ, Vasilieva N, Sui J, Wong SK, Berne MA, et al. AngiotensinConverting Enzyme 2 Is a Functional Receptor for the SARS Coronavirus. Nature (2003) 426:450-4. doi: 10.1038/nature02145

80. Raj VS, Mou H, Smits SL, Dekkers DH, Müller MA, Dijkman R, et al. Dipeptidyl Peptidase 4 Is a Functional Receptor for the Emerging Human Coronavirus-EMC. Nature (2013) 495:251-4. doi: 10.1038/nature12005

81. Bertram S, Dijkman R, Habjan M, Heurich A, Gierer S, Glowacka I, et al. TMPRSS2 Activates the Human Coronavirus 229E for CathepsinIndependent Host Cell Entry and Is Expressed in Viral Target Cells in the Respiratory Epithelium. J Virol (2013) 87:6150-60. doi: 10.1128/jvi.03372-12

82. Glowacka I, Bertram S, Müller MA, Allen P, Soilleux E, Pfefferle S, et al. Evidence That TMPRSS2 Activates the Severe Acute Respiratory Syndrome Coronavirus Spike Protein for Membrane Fusion and Reduces Viral Control by the Humoral Immune Response. J Virol (2011) 85:4122-34. doi: 10.1128/ jvi.02232-10

83. Ivanovic T, Choi JL, Whelan SP, van Oijen AM, Harrison SC. InfluenzaVirus Membrane Fusion by Cooperative Fold-Back of Stochastically Induced Hemagglutinin Intermediates. Elife (2013) 2:e00333. doi: 10.7554/ eLife. 00333

84. Magnus C, Rusert P, Bonhoeffer S, Trkola A, Regoes RR. Estimating the Stoichiometry of Human Immunodeficiency Virus Entry. J Virol (2009) 83:1523-31. doi: 10.1128/jvi.01764-08

85. Charrin S, le Naour F, Silvie O, Milhiet PE, Boucheix C, Rubinstein E. Lateral Organization of Membrane Proteins: Tetraspanins Spin Their Web. Biochem $J$ (2009) 420:133-54. doi: 10.1042/bj20082422

86. Gunasekaran M, Bansal S, Ravichandran R, Sharma M, Perincheri S, Rodriguez F, et al. Respiratory Viral Infection in Lung Transplantation Induces Exosomes That Trigger Chronic Rejection. J Heart Lung Transplant (2020) 39:379-88. doi: 10.1016/j.healun.2019.12.009

87. Wan Y, Shang J, Graham R, Baric RS, Li F. Receptor Recognition by the Novel Coronavirus From Wuhan: An Analysis Based on Decade-Long Structural Studies of SARS Coronavirus. J Virol (2020) 94. doi: 10.1128/ jvi.00127-20

88. Devaux CA, Rolain JM, Raoult D. ACE2 Receptor Polymorphism: Susceptibility to SARS-CoV-2, Hypertension, Multi-Organ Failure, and COVID-19 Disease Outcome. J Microbiol Immunol Infect (2020) 53:42535. doi: $10.1016 /$ j.jmii.2020.04.015
89. Gunasekaran M, Xu Z, Nayak DK, Sharma M, Hachem R, Walia R, et al. Donor-Derived Exosomes With Lung Self-Antigens in Human Lung Allograft Rejection. Am J Transplant (2017) 17:474-84. doi: 10.1111/ ajt.13915

90. Bukong TN, Hou W, Kodys K, Szabo G. Ethanol Facilitates Hepatitis C Virus Replication Via Up-Regulation of GW182 and Heat Shock Protein 90 in Human Hepatoma Cells. Hepatology (2013) 57:70-80. doi: 10.1002/ hep. 26010

91. Wu Y, Zhao T, Deng R, Xia X, Li B, Wang X. A Study of Differential circRNA and lncRNA Expressions in COVID-19-Infected Peripheral Blood. Sci Rep (2021) 11:7991. doi: 10.1038/s41598-021-86134-0

92. Barberis E, Vanella VV, Falasca M, Caneapero V, Cappellano G, Raineri D, et al. Circulating Exosomes Are Strongly Involved in SARS-CoV-2 Infection. Front Mol Biosci (2021) 8:632290. doi: 10.3389/fmolb.2021.632290

93. Gambardella J, Sardu C, Morelli MB, Messina V, Castellanos V, Marfella R, et al. Exosomal microRNAs Drive Thrombosis in COVID-19. medRxiv (2020), 2020.06.16.20133256. doi: 10.1101/2020.06.16.20133256

94. Song JW, Lam SM, Fan X, Cao WJ, Wang SY, Tian H, et al. Omics-Driven Systems Interrogation of Metabolic Dysregulation in COVID-19 Pathogenesis. Cell Metab (2020) 32:188-202.e5. doi: 10.1016/ j.cmet.2020.06.016

95. Chahar HS, Corsello T, Kudlicki AS, Komaravelli N, Casola A. Respiratory Syncytial Virus Infection Changes Cargo Composition of Exosome Released From Airway Epithelial Cells. Sci Rep (2018) 8:387. doi: 10.1038/s41598-017$18672-5$

96. Coperchini F, Chiovato L, Croce L, Magri F, Rotondi M. The Cytokine Storm in COVID-19: An Overview of the Involvement of the Chemokine/ Chemokine-Receptor System. Cytokine Growth Factor Rev (2020) 53:25-32. doi: 10.1016/j.cytogfr.2020.05.003

97. Jamilloux Y, Henry T, Belot A, Viel S, Fauter M, El Jammal T, et al. Should We Stimulate or Suppress Immune Responses in COVID-19? Cytokine and Anti-Cytokine Interventions. Autoimmun Rev (2020) 19:102567. doi: 10.1016/j.autrev.2020.102567

98. Zheng Y, Zhang Y, Chi H, Chen S, Peng M, Luo L, et al. The Hemocyte Counts as a Potential Biomarker for Predicting Disease Progression in COVID-19: A Retrospective Study. Clin Chem Lab Med (2020) 58:110615. doi: $10.1515 / \mathrm{cclm}-2020-0377$

99. Lippi G, Plebani M, Henry BM. Thrombocytopenia Is Associated With Severe Coronavirus Disease 2019 (COVID-19) Infections: A Meta-Analysis. Clin Chim Acta (2020) 506:145-8. doi: 10.1016/j.cca.2020.03.022

100. Shen B, Yi X, Sun Y, Bi X, Du J, Zhang C, et al. Proteomic and Metabolomics Characterization of COVID-19 Patient Sera. Cell (2020) 182:59-72.e15. doi: 10.1016/j.cell.2020.05.032

101. Grifoni A, Weiskopf D, Ramirez SI, Mateus J, Dan JM, Moderbacher CR, et al. Targets of T Cell Responses to SARS-CoV-2 Coronavirus in Humans With COVID-19 Disease and Unexposed Individuals. Cell (2020) 181:1489501.e15. doi: 10.1016/j.cell.2020.05.015

102. Chen W. A Potential Treatment of COVID-19 With TGF- $\beta$ Blockade. Int J Biol Sci (2020) 16:1954-5. doi: 10.7150/ijbs.46891

103. tenOever BR. RNA Viruses and the Host microRNA Machinery. Nat Rev Microbiol (2013) 11:169-80. doi: 10.1038/nrmicro2971

104. Rosell A, Havervall S, von Meijenfeldt F, Hisada Y, Aguilera K, Grover SP, et al. Patients With COVID-19 Have Elevated Levels of Circulating Extracellular Vesicle Tissue Factor Activity That is Associated With Severity and Mortality. Arterioscler Thromb Vasc Biol (2020) 41: Atvbaha120315547. doi: 10.1161/atvbaha.120.315547

105. Zhang Y, Bi J, Huang J, Tang Y, Du S, Li P. Exosome: A Review of its Classification, Isolation Techniques, Storage, Diagnostic and Targeted Therapy Applications. Int J Nanomed (2020) 15:6917-34. doi: 10.2147/ ijn.S264498

106. Atluri S, Manchikanti L, Hirsch JA. Expanded Umbilical Cord Mesenchymal Stem Cells (UC-MSCs) as a Therapeutic Strategy in Managing Critically Ill Covid-19 Patients: The Case for Compassionate Use. Pain Physician (2020) 23:E71-83.

107. Leng Z, Zhu R, Hou W, Feng Y, Yang Y, Han Q, et al. Transplantation of ACE2(-) Mesenchymal Stem Cells Improves the Outcome of Patients With COVID-19 Pneumonia. Pain Physician (2020) 23(2):E71-83. doi: 10.14336/ ad.2020.0228 
108. Alexandersen S, Chamings A, Bhatta TR. Sars-CoV-2 Genomic and Subgenomic RNAs in Diagnostic Samples Are Not an Indicator of Active Replication. Nat Commun (2020) 11:6059. doi: 10.1038/s41467-020-19883-7

109. Snijder EJ, van der Meer Y, Zevenhoven-Dobbe J, Onderwater JJ, van der Meulen J, Koerten HK, et al. Ultrastructure and Origin of Membrane Vesicles Associated With the Severe Acute Respiratory Syndrome Coronavirus Replication Complex. J Virol (2006) 80:5927-40. doi: 10.1128/jvi.02501-05

110. Schneider DJ, Speth JM, Penke LR, Wettlaufer SH, Swanson JA, PetersGolden M. Mechanisms and Modulation of Microvesicle Uptake in a Model of Alveolar Cell Communication. J Biol Chem (2017) 292:20897-910. doi: 10.1074/jbc.M117.792416

111. Liang B, Chen J, Li T, Wu H, Yang W, Li Y, et al. Clinical Remission of a Critically Ill COVID-19 Patient Treated by Human Umbilical Cord Mesenchymal Stem Cells: A Case Report. Med (Baltimore) (2020) 99: e21429. doi: $10.1097 / \mathrm{md} .0000000000021429$

112. Shu L, Niu C, Li R, Huang T, Wang Y, Huang M, et al. Treatment of Severe COVID-19 With Human Umbilical Cord Mesenchymal Stem Cells. Stem Cell Res Ther (2020) 11:361. doi: 10.1186/s13287-020-01875-5

113. Bari E, Ferrarotti I, Torre ML, Corsico AG, Perteghella S. Mesenchymal Stem/Stromal Cell Secretome for Lung Regeneration: The Long Way Through "Pharmaceuticalization" for the Best Formulation. J Control Release (2019) 309:11-24. doi: 10.1016/j.jconrel.2019.07.022

114. Tsiapalis D, O'Driscoll L. Mesenchymal Stem Cell Derived Extracellular Vesicles for Tissue Engineering and Regenerative Medicine Applications. Cells (2020) 9. doi: 10.3390/cells9040991

115. Bari E, Ferrarotti I, Saracino L, Perteghella S, Torre ML, Corsico AG. Mesenchymal Stromal Cell Secretome for Severe COVID-19 Infections: Premises for the Therapeutic Use. Cells (2020) 9. doi: 10.3390/cells9040924

116. Worthington EN, Hagood JS. Therapeutic Use of Extracellular Vesicles for Acute and Chronic Lung Disease. Int J Mol Sci (2020) 21. doi: 10.3390/ ijms 21072318

117. Mahida RY, Chotalia M, Alderman J, Patel C, Hayden A, Desai R, et al. Characterisation and Outcomes of ARDS Secondary to Pneumonia in Patients With and Without SARS-CoV-2: A Single-Centre Experience. BMJ Open Respir Res (2020) 7. doi: 10.1136/bmjresp-2020-000731

118. Bjørge IM, Kim SY, Mano JF, Kalionis B, Chrzanowski W. Extracellular Vesicles, Exosomes and Shedding Vesicles in Regenerative Medicine - a New Paradigm for Tissue Repair. Biomater Sci (2017) 6:60-78. doi: 10.1039/ c7bm00479f

119. El Andaloussi S, Lakhal S, Mäger I, Wood MJ. Exosomes for Targeted siRNA Delivery Across Biological Barriers. Adv Drug Deliv Rev (2013) 65:391-7. doi: $10.1016 /$ j.addr.2012.08.008

120. Derkus B, Emregul KC, Emregul E. A New Approach in Stem Cell ResearchExosomes: Their Mechanism of Action Via Cellular Pathways. Cell Biol Int (2017) 41:466-75. doi: 10.1002/cbin.10742

121. Basalova N, Sagaradze G, Arbatskiy M, Evtushenko E, Kulebyakin K, Grigorieva O, et al. Secretome of Mesenchymal Stromal Cells Prevents Myofibroblasts Differentiation by Transferring Fibrosis-Associated microRNAs Within Extracellular Vesicles. Cells (2020) 9. doi: 10.3390/ cells 9051272

122. Silva JD, de Castro LL, Braga CL, Oliveira GP, Trivelin SA, Barbosa-Junior CM, et al. Mesenchymal Stromal Cells Are More Effective Than Their Extracellular Vesicles at Reducing Lung Lnjury Regardless of Acute Respiratory Distress Syndrome Etiology. Stem Cells Int (2019) 2019:8262849. doi: 10.1155/2019/8262849

123. Bedford JG, Infusini G, Dagley LF, Villalon-Letelier F, Zheng MZM, BennettWood V, et al. Airway Exosomes Released During Influenza Virus Infection Serve as a Key Component of the Antiviral Innate Immune Response. Front Immunol (2020) 11:887. doi: 10.3389/fimmu.2020.00887

124. Abraham A, Krasnodembskaya A. Mesenchymal Stem Cell-Derived Extracellular Vesicles for the Treatment of Acute Respiratory Distress Syndrome. Stem Cells Transl Med (2020) 9:28-38. doi: 10.1002/sctm.19-0205

125. Wang Y, Zhang D, Du G, Du R, Zhao J, Jin Y, et al. Remdesivir in Adults With Severe COVID-19: A Randomised, Double-Blind, Placebo-Controlled, Multicentre Trial. Lancet (2020) 395:1569-78. doi: 10.1016/s0140-6736(20) $31022-9$
126. Mahévas M, Tran V-T, Roumier M, Chabrol A, Paule R, Guillaud C, et al. No Evidence of Clinical Efficacy of Hydroxychloroquine in Patients Hospitalised for COVID-19 Infection and Requiring Oxygen: Results of a Study Using Routinely Collected Data to Emulate a Target Trial. medRxiv (2020). doi: 10.1101/2020.04.10.20060699. 2020.04.10.20060699.

127. Alzghari SK, Acuña VS. Supportive Treatment With Tocilizumab for COVID-19: A Systematic Review. J Clin Virol (2020) 127:104380. doi: 10.1016/j.jcv.2020.104380

128. Chen YM, Wu CH, Chang KM, Zhang YX, Xu N, Yu TY, et al. Study of Atmospheric-Rressure Plasma Enhanced Chemical Vapor Deposition Fabricated Indium Gallium Zinc Oxide Thin Film Transistors With inSitu Hydrogen Plasma Treatment. J Nanosci Nanotechnol (2020) 20:4110-3. doi: 10.1166/jnn.2020.17556

129. Tian X, Li C, Huang A, Xia S, Lu S, Shi Z, et al. Potent Binding of 2019 Novel Coronavirus Spike Protein by a SARS Coronavirus-Specific Human Monoclonal Antibody. Emerg Microbes Infect (2020) 9:382-5. doi: 10.1080/22221751.2020.1729069

130. Casadevall A, Pirofski LA. The Ebola Epidemic Crystallizes the Potential of Passive Antibody Therapy for Infectious Diseases. PloS Pathog (2015) 11: e1004717. doi: 10.1371/journal.ppat.1004717

131. Liu J, Li S, Liu J, Liang B, Wang X, Wang H, et al. Longitudinal Characteristics of Lymphocyte Responses and Cytokine Profiles in the Peripheral Blood of SARS-CoV-2 Infected Patients. EBioMedicine (2020) 55:102763. doi: 10.1016/j.ebiom.2020.102763

132. Chen C, Zhang XR, Ju ZY, He WF. [Advances in the Research of Mechanism and Related Immunotherapy on the Cytokine Storm Induced by Coronavirus Disease 2019]. Zhonghua Shao Shang Za Zhi (2020) 36:4715. doi: 10.3760/cma.j.cn501120-20200224-00088

133. Zhou H, Lu S, Chen J, Wei N, Wang D, Lyu H, et al. The Landscape of Cognitive Function in Recovered COVID-19 Patients. J Psychiatr Res (2020) 129:98-102. doi: 10.1016/j.jpsychires.2020.06.022

134. Reynolds A, Leake D, Boese Q, Scaringe S, Marshall WS, Khvorova A. Rational siRNA Design for RNA Interference. Nat Biotechnol (2004) 22:32630. doi: $10.1038 /$ nbt936

135. Wu CJ, Huang HW, Liu CY, Hong CF, Chan YL. Inhibition of SARS-CoV Replication by siRNA. Antiviral Res (2005) 65:45-8. doi: 10.1016/ j.antiviral.2004.09.005

136. Klyachko NL, Arzt CJ, Li SM, Gololobova OA, Batrakova EV. Extracellular Vesicle-Based Therapeutics: Preclinical and Clinical Investigations. Pharmaceutics (2020) 12. doi: 10.3390/pharmaceutics12121171

137. Das S, Ansel KM, Bitzer M, Breakefield XO, Charest A, Galas DJ, et al. The Extracellular RNA Communication Consortium: Establishing Foundational Knowledge and Technologies for Extracellular RNA Research. Cell (2019) 177:231-42. doi: 10.1016/j.cell.2019.03.023

138. Fisher SA, Cutler A, Doree C, Brunskill SJ, Stanworth SJ, Navarrete C, et al. Mesenchymal Stromal Cells as Treatment or Prophylaxis for Acute or Chronic Graft-Versus-Host Disease in Haematopoietic Stem Cell Transplant (HSCT) Recipients With a Haematological Condition. Cochrane Database Syst Rev (2019) 1:Cd009768. doi: 10.1002/ 14651858.CD009768.pub2

139. Päth G, Perakakis N, Mantzoros CS, Seufert J. Stem Cells in the Treatment of Diabetes Mellitus - Focus on Mesenchymal Stem Cells. Metabolism (2019) 90:1-15. doi: 10.1016/j.metabol.2018.10.005

140. Weiss ARR, Dahlke MH. Immunomodulation by Mesenchymal Stem Cells (MSCs): Mechanisms of Action of Living, Apoptotic, and Dead MSCs. Front Immunol (2019) 10:1191. doi: 10.3389/fimmu.2019.01191

141. Shende P, Subedi M. Pathophysiology, Mechanisms and Applications of Mesenchymal Stem Cells for the Treatment of Spinal Cord Injury. BioMed Pharmacother (2017) 91:693-706. doi: 10.1016/j.biopha.2017.04.126

142. Katsha AM, Ohkouchi S, Xin H, Kanehira M, Sun R, Nukiwa T, et al. Paracrine Factors of Multipotent Stromal Cells Ameliorate Lung Injury in an Elastase-Induced Emphysema Model. Mol Ther (2011) 19:196-203. doi: $10.1038 / \mathrm{mt} .2010 .192$

143. Zhu B, Zheng F, Liu N, Zhu MH, Xie J, Ye JR, et al. Diagnostic Value of Surfactant Protein-A in Severe Acute Pancreatitis-Induced Acute Respiratory Distress Syndrome. Med Sci Monit (2014) 20:1728-34. doi: $10.12659 / \mathrm{msm} .891272$ 
144. Tang XD, Shi L, Monsel A, Li XY, Zhu HL, Zhu YG, et al. Mesenchymal Stem Cell Microvesicles Attenuate Acute Lung Injury in Mice Partly Mediated by Ang-1 mRNA. Stem Cells (2017) 35:1849-59. doi: 10.1002/stem.2619

145. Morrison TJ, Jackson MV, Cunningham EK, Kissenpfennig A, McAuley DF, O'Kane CM, et al. Mesenchymal Stromal Cells Modulate Macrophages in Clinically Relevant Lung Injury Models by Extracellular Vesicle Mitochondrial Transfer. Am J Respir Crit Care Med (2017) 196:1275-86. doi: 10.1164/rccm.201701-0170OC

146. Wang M, Yuan Q, Xie L. Mesenchymal Stem Cell-Based Immunomodulation: Properties and Clinical Application. Stem Cells Int (2018) 2018:3057624. doi: 10.1155/2018/3057624

147. Lee JH, Park J, Lee JW. Therapeutic Use of Mesenchymal Stem Cell-Derived Extracellular Vesicles in Acute Lung Injury. Transfusion (2019) 59:876-83. doi: $10.1111 /$ trf.14838

148. Xu Z, Shi L, Wang Y, Zhang J, Huang L, Zhang C, et al. Pathological Findings of COVID-19 Associated With Acute Respiratory Distress Syndrome. Lancet Respir Med (2020) 8:420-2. doi: 10.1016/s2213-2600(20)30076-x

149. Li JW, Wei L, Han Z, Chen Z. Mesenchymal Stromal Cells-Derived Exosomes Alleviate Ischemia/Reperfusion Injury in Mouse Lung by Transporting Anti-Apoptotic miR-21-5p. Eur J Pharmacol (2019) 852:6876. doi: 10.1016/j.ejphar.2019.01.022

150. Bari E, Ferrarotti I, Di Silvestre D, Grisoli P, Barzon V, Balderacchi A, et al. Adipose Mesenchymal Extracellular Vesicles as Alpha-1-Antitrypsin Physiological Delivery Systems for Lung Regeneration. Cells (2019) 8. doi: $10.3390 /$ cells 8090965

151. Kim SY, Lee JH, Kim HJ, Park MK, Huh JW, Ro JY, et al. Mesenchymal Stem Cell-Conditioned Media Recovers Lung Fibroblasts From Cigarette SmokeInduced Damage. Am J Physiol Lung Cell Mol Physiol (2012) 302:L891-908. doi: 10.1152/ajplung.00288.2011

152. Hao Q, Gudapati V, Monsel A, Park JH, Hu S, Kato H, et al. Mesenchymal Stem Cell-Derived Extracellular Vesicles Decrease Lung Injury in Mice. J Immunol (2019) 203:1961-72. doi: 10.4049/jimmunol.1801534

153. Zeng SL, Wang LH, Li P, Wang W, Yang J. Mesenchymal Stem Cells Abrogate Experimental Asthma by Altering Dendritic Cell Function. Mol Med Rep (2015) 12:2511-20. doi: 10.3892/mmr.2015.3706

154. Gennai S, Monsel A, Hao Q, Park J, Matthay MA, Lee JW. Microvesicles Derived From Human Mesenchymal Stem Cells Restore Alveolar Fluid Clearance in Human Lungs Rejected for Transplantation. Am J Transplant (2015) 15:2404-12. doi: 10.1111/ajt.13271

155. Chang CL, Chen HH, Chen KH, Chiang JY, Li YC, Lin HS, et al. AdiposeDerived Mesenchymal Stem Cell-Derived Exosomes Markedly Protected the Brain Against Sepsis Syndrome Induced Injury in Rat. Am J Transl Res (2019) 11:3955-71.

156. Zemans RL, Matthay MA. What Drives Neutrophils to the Alveoli in ARDS? Thorax (2017) 72:1-3. doi: 10.1136/thoraxjnl-2016-209170

157. Wichmann D, Sperhake JP, Lütgehetmann M, Steurer S, Edler C, Heinemann A, et al. Autopsy Findings and Venous Thromboembolism in Patients With COVID-19: A Prospective Cohort Study. Ann Intern Med (2020) 173:268-77. doi: 10.7326/m20-2003

158. Park J, Kim S, Lim H, Liu A, Hu S, Lee J, et al. Therapeutic Effects of Human Mesenchymal Stem Cell Microvesicles in an Ex Vivo Perfused Human Lung Injured With Severe E. Coli Pneumonia. Thorax (2019) 74:43-50. doi: 10.1136/thoraxjnl-2018-211576

159. Khatri M, Richardson LA, Meulia T. Mesenchymal Stem Cell-Derived Extracellular Vesicles Attenuate Influenza Virus-Induced Acute Lung Injury in a Pig Model. Stem Cell Res Ther (2018) 9:17. doi: 10.1186/ s13287-018-0774-8

160. Ahmadi M, Rezaie J. Tumor Cells Derived-Exosomes as Angiogenenic Agents: Possible Therapeutic Implications. J Transl Med (2020) 18:249. doi: 10.1186/s12967-020-02426-5

161. Potente M, Gerhardt H, Carmeliet P. Basic and Therapeutic Aspects of Angiogenesis. Cell (2011) 146:873-87. doi: 10.1016/j.cell.2011.08.039

162. Chaineau M, Danglot L, Galli T. Multiple Roles of the Vesicular-SNARE TIVAMP in Post-Golgi and Endosomal Trafficking. FEBS Lett (2009) 583:3817-26. doi: 10.1016/j.febslet.2009.10.026

163. Wang J, De Veirman K, Faict S, Frassanito MA, Ribatti D, Vacca A, et al. Multiple Myeloma Exosomes Establish a Favourable Bone Marrow
Microenvironment With Enhanced Angiogenesis and Immunosuppression. J Pathol (2016) 239:162-73. doi: 10.1002/path.4712

164. Francescone R, Scully S, Bentley B, Yan W, Taylor SL, Oh D, et al. GlioblastomaDerived Tumor Cells Induce Vasculogenic Mimicry Through Flk-1 Protein Activation. J Biol Chem (2012) 287:24821-31. doi: 10.1074/jbc.M111.334540

165. Lang HL, Hu GW, Chen Y, Liu Y, Tu W, Lu YM, et al. Glioma Cells Promote Angiogenesis Through the Release of Exosomes Containing Long NonCoding RNA POU3F3. Eur Rev Med Pharmacol Sci (2017) 21:959-72.

166. Kucharzewska P, Christianson HC, Welch JE, Svensson KJ, Fredlund E, Ringnér M, et al. Exosomes Reflect the Hypoxic Status of Glioma Cells and Mediate Hypoxia-Dependent Activation of Vascular Cells During Tumor Development. Proc Natl Acad Sci USA (2013) 110:7312-7. doi: 10.1073/ pnas. 1220998110

167. Akbari A, Rezaie J. Potential Therapeutic Application of Mesenchymal Stem Cell-Derived Exosomes in SARS-CoV-2 Pneumonia. Stem Cell Res Ther (2020) 11:356. doi: 10.1186/s13287-020-01866-6

168. Zani-Ruttenstock E, Antounians L, Khalaj K, Figueira RL, Zani A. The Role of Exosomes in the Treatment, Prevention, Diagnosis, and Pathogenesis of COVID-19. Eur J Pediatr Surg (2021). doi: 10.1055/s-0041-1731294

169. Huang Y, Li Y, Zhang H, Zhao R, Jing R, Xu Y, et al. Zika Virus Propagation and Release in Human Fetal Astrocytes Can be Suppressed by Neutral Sphingomyelinase-2 Inhibitor Gw4869. Cell Discov (2018) 4:19. doi: 10.1038/ s41421-018-0017-2

170. Pegtel DM, Cosmopoulos K, Thorley-Lawson DA, van Eijndhoven MA, Hopmans ES, Lindenberg JL, et al. Functional Delivery of Viral miRNAs Via Exosomes. Proc Natl Acad Sci USA (2010) 107:6328-33. doi: 10.1073/ pnas. 0914843107

171. Catalano M, O’Driscoll L. Inhibiting Extracellular Vesicles Formation and Release: A Review of EV Inhibitors. J Extracell Vesicles (2020) 9:1703244. doi: 10.1080/20013078.2019.1703244

172. Fox JE, Austin CD, Reynolds CC, Steffen PK. Evidence That AgonistInduced Activation of Calpain Causes the Shedding of ProcoagulantContaining Microvesicles From the Membrane of Aggregating Platelets. J Biol Chem (1991) 266:13289-95.

173. Crespin M, Vidal C, Picard F, Lacombe C, Fontenay M. Activation of PAK1/ 2 During the Shedding of Platelet Microvesicles. Blood Coagul Fibrinolysis (2009) 20:63-70. doi: 10.1097/MBC.0b013e32831bc310

174. Mallick RL, Kumari S, Singh N, Sonkar VK, Dash D. Prion Protein Fragment (106-126) Induces Prothrombotic State by Raising Platelet Intracellular Calcium and Microparticle Release. Cell Calcium (2015) 57:300-11. doi: 10.1016/j.ceca.2015.02.002

175. Atanassoff AP, Wolfmeier H, Schoenauer R, Hostettler A, Ring A, Draeger A, et al. Microvesicle Shedding and Lysosomal Repair Fulfill Divergent Cellular Needs During the Repair of Streptolysin O-Induced Plasmalemmal Damage. PloS One (2014) 9:e89743. doi: 10.1371/journal.pone.0089743

176. Jorfi S, Ansa-Addo EA, Kholia S, Stratton D, Valley S, Lange S, et al. Inhibition of Microvesiculation Sensitizes Prostate Cancer Cells to Chemotherapy and Reduces Docetaxel Dose Required to Limit Tumor Growth In Vivo. Sci Rep (2015) 5:13006. doi: 10.1038/srep13006

177. Barnard DL, Hubbard VD, Burton J, Smee DF, Morrey JD, Otto MJ, et al. Inhibition of Severe Acute Respiratory Syndrome-Associated Coronavirus (SARSCoV) by Calpain Inhibitors and Beta-D-N4-Hydroxycytidine. Antivir Chem Chemother (2004) 15:15-22. doi: 10.1177/095632020401500102

178. Wennerberg K, Rossman KL, Der CJ. The Ras Superfamily at a Glance. J Cell Sci (2005) 118:843-6. doi: 10.1242/jcs.01660

179. Oh HJ, Shin Y, Chung S, Hwang DW, Lee DS. Convective Exosome-Tracing Microfluidics for Analysis of Cell-Non-Autonomous Neurogenesis. Biomaterials (2017) 112:82-94. doi: 10.1016/j.biomaterials.2016.10.006

180. Datta A, Kim H, Lal M, McGee L, Johnson A, Moustafa AA, et al. Manumycin A Suppresses Exosome Biogenesis and Secretion Via Targeted Inhibition of Ras/Raf/ERK1/2 Signaling and Hnrnp H1 in CastrationResistant Prostate Cancer Cells. Cancer Lett (2017) 408:73-81. doi: 10.1016/j.canlet.2017.08.020

181. Zhou X, Zhang W, Yao Q, Zhang H, Dong G, Zhang M, et al. Exosome Production and its Regulation of EGFR During Wound Healing in Renal Tubular Cells. Am J Physiol Renal Physiol (2017) 312:F963-f70. doi: 10.1152/ ajprenal.00078.2017 
182. Abid Hussein MN, Böing AN, Sturk A, Hau CM, Nieuwland R. Inhibition of Microparticle Release Triggers Endothelial Cell Apoptosis and Detachment. Thromb Haemost (2007) 98:1096-107. doi: 10.1160/th05-04-0231

183. Kim M, Ham A, Kim KY, Brown KM, Lee HT. The Volatile Anesthetic Isoflurane Increases Endothelial Adenosine Generation Via Microparticle Ecto-5'-Nucleotidase (CD73) Release. PloS One (2014) 9:e99950. doi: 10.1371/journal.pone.0099950

184. Latham SL, Chaponnier C, Dugina V, Couraud PO, Grau GE, Combes V. Cooperation Between $\beta$ - and $\gamma$-Cytoplasmic Actins in the Mechanical Regulation of Endothelial Microparticle Formation. FASEB J (2013) 27:672-83. doi: 10.1096/fj.12-216531

185. Sapet C, Simoncini S, Loriod B, Puthier D, Sampol J, Nguyen C, et al. Thrombin-Induced Endothelial Microparticle Generation: Identification of a Novel Pathway Involving ROCK-II Activation by Caspase-2. Blood (2006) 108:1868-76. doi: 10.1182/blood-2006-04-014175

186. Tramontano AF, O’Leary J, Black AD, Muniyappa R, Cutaia MV, El-Sherif N. Statin Decreases Endothelial Microparticle Release From Human Coronary Artery Endothelial Cells: Implication for the Rho-Kinase Pathway. Biochem Biophys Res Commun (2004) 320:34-8. doi: 10.1016/j.bbrc.2004.05.127

187. Dai H, Zhang S, Du X, Zhang W, Jing R, Wang X, et al. Rhoa Inhibitor Suppresses the Production of Microvesicles and Rescues High Ventilation Induced Lung Injury. Int Immunopharmacol (2019) 72:74-81. doi: 10.1016/ j.intimp.2019.03.059

188. Abedi F, Rezaee R, Karimi G. Plausibility of Therapeutic Effects of Rho Kinase Inhibitors Against Severe Acute Respiratory Syndrome Coronavirus 2 (Covid-19). Pharmacol Res (2020) 156:104808. doi: 10.1016/j.phrs. 2020.104808

189. Arenz C. Small Molecule Inhibitors of Acid Sphingomyelinase. Cell Physiol Biochem (2010) 26:1-8. doi: 10.1159/000315100

190. Lin HP, Singla B, Ghoshal P, Faulkner JL, Cherian-Shaw M, O'Connor PM, et al. Identification of Novel Macropinocytosis Inhibitors Using a Rational Screen of Food and Drug Administration-Approved Drugs. Br J Pharmacol (2018) 175:3640-55. doi: 10.1111/bph.14429

191. Sancho-Albero M, Sebastián V, Sesé J, Pazo-Cid R, Mendoza G, Arruebo M, et al. Isolation of Exosomes From Whole Blood by a New Microfluidic Device: Proof of Concept Application in the Diagnosis and Monitoring of Pancreatic Cancer. J Nanobiotechnol (2020) 18:150. doi: 10.1186/s12951020-00701-7

192. Pardridge WM. Drug Transport Across the Blood-Brain Barrier. J Cereb Blood Flow Metab (2012) 32:1959-72. doi: 10.1038/jcbfm.2012.126

193. Druzhkova TA, Yakovlev AA. Exosome Drug Delivery Through the BloodBrain Barrier: Experimental Approaches and Potential Applications. Neurochemical J (2018) 12:195-204. doi: 10.1134/S1819712418030030

194. Shah D, Das P, Alam MA, Mahajan N, Romero F, Shahid M, et al. MicroRNA-34a Promotes Endothelial Dysfunction and MitochondrialMediated Apoptosis in Murine Models of Acute Lung Injury. Am J Respir Cell Mol Biol (2019) 60:465-77. doi: 10.1165/rcmb.2018-0194OC

195. Song Y, Dou H, Li X, Zhao X, Li Y, Liu D, et al. Exosomal miR-146a Contributes to the Enhanced Therapeutic Efficacy of Interleukin-1 $\beta$-Primed Mesenchymal Stem Cells Against Sepsis. Stem Cells (2017) 35:1208-21. doi: $10.1002 /$ stem. 2564

196. Vader P, Mol EA, Pasterkamp G, Schiffelers RM. Extracellular Vesicles for Drug Delivery. Adv Drug Deliv Rev (2016) 106:148-56. doi: 10.1016/ j.addr.2016.02.006

197. Gupta A, Kashte S, Gupta M, Rodriguez HC, Gautam SS, Kadam S. Mesenchymal Stem Cells and Exosome Therapy for COVID-19: Current Status and Future Perspective. Hum Cell (2020) 33:907-18. doi: 10.1007/ s13577-020-00407-w

198. Zhou H, Fang Y, Xu T, Ni WJ, Shen AZ, Meng XM. Potential Therapeutic Targets and Promising Drugs for Combating SARS-CoV-2. Br J Pharmacol (2020) 177:3147-61. doi: 10.1111/bph.15092

199. Dinh PC, Paudel D, Brochu H, Popowski KD, Gracieux MC, Cores J, et al. Inhalation of Lung Spheroid Cell Secretome and Exosomes Promotes Lung Repair in Pulmonary Fibrosis. Nat Commun (2020) 11:1064. doi: 10.1038/ s41467-020-14344-7

200. van Haren FMP, Page C, Laffey JG, Artigas A, Camprubi-Rimblas M, Nunes Q, et al. Nebulised Heparin as a Treatment for COVID-19: Scientific
Rationale and a Call for Randomised Evidence. Crit Care (2020) 24:454. doi: $10.1186 /$ s13054-020-03148-2

201. Ghaebi M, Osali A, Valizadeh H, Roshangar L, Ahmadi M. Vaccine Development and Therapeutic Design for 2019-nCoV/SARS-CoV-2: Challenges and Chances. J Cell Physiol (2020) 235:9098-109. doi: 10.1002/ jcp.29771

202. Omolo CA, Soni N, Fasiku VO, Mackraj I, Govender T. Update on Therapeutic Approaches and Emerging Therapies for SARS-CoV-2 Virus. Eur J Pharmacol (2020) 883:173348. doi: 10.1016/j.ejphar.2020.173348

203. Sabanovic B, Piva F, Cecati M, Giulietti M. Promising Extracellular VesicleBased Vaccines Against Viruses, Including SARS-CoV-2. Biol (Basel) (2021) 10. doi: 10.3390/biology10020094

204. Maji S, Yan IK, Parasramka M, Mohankumar S, Matsuda A, Patel T. In Vivo Toxicology Studies of Extracellular Vesicles. J Appl Toxicol (2017) 37:310-8. doi: $10.1002 /$ jat.3362

205. Mendt M, Kamerkar S, Sugimoto H, McAndrews KM, Wu CC, Gagea M, et al. Generation and Testing of Clinical-Grade Exosomes for Pancreatic Cancer. JCI Insight (2018) 3. doi: 10.1172/jci.insight.99263

206. Saleh AF, Lázaro-Ibáñez E, Forsgard MA, Shatnyeva O, Osteikoetxea X, Karlsson F, et al. Extracellular Vesicles Induce Minimal Hepatotoxicity and Immunogenicity. Nanoscale (2019) 11:6990-7001. doi: 10.1039/c8nr08720b

207. Admyre C, Johansson SM, Paulie S, Gabrielsson S. Direct Exosome Stimulation of Peripheral Human T Cells Detected by ELISPOT. Eur J Immunol (2006) 36:1772-81. doi: 10.1002/eji.200535615

208. Kuate S, Cinatl J, Doerr HW, Uberla K. Exosomal Vaccines Containing the S Protein of the SARS Coronavirus Induce High Levels of Neutralizing Antibodies. Virology (2007) 362:26-37. doi: 10.1016/j.virol.2006.12.011

209. Li S, Li S, Wu S, Chen L. Exosomes Modulate the Viral Replication and Host Immune Responses in HBV Infection. BioMed Res Int (2019) 2019:2103943. doi: $10.1155 / 2019 / 2103943$

210. Nikfarjam S, Rezaie J, Kashanchi F, Jafari R. Dexosomes as a Cell-Free Vaccine for Cancer Immunotherapy. J Exp Clin Cancer Res (2020) 39:258. doi: 10.1186/s13046-020-01781-x

211. Rezaie J, Aslan C, Ahmadi M, Zolbanin NM, Kashanchi F, Jafari R. The Versatile Role of Exosomes in Human Retroviral Infections: From Immunopathogenesis to Clinical Application. Cell Biosci (2021) 11:19. doi: 10.1186/s13578-021-00537-0

212. Elashiry M, Elsayed R, Elashiry MM, Rashid MH, Ara R, Arbab AS, et al. Proteomic Characterization, Biodistribution, and Functional Studies of Immune-Therapeutic Exosomes: Implications for Inflammatory Lung Diseases. Front Immunol (2021) 12:636222. doi: 10.3389/fimmu.2021.636222

213. Elashiry M, Elashiry MM, Elsayed R, Rajendran M, Auersvald C, Zeitoun R, et al. Dendritic Cell Derived Exosomes Loaded With Immunoregulatory Cargo Reprogram Local Immune Responses and Inhibit Degenerative Bone Disease In Vivo. J Extracell Vesicles (2020) 9:1795362. doi: 10.1080/ 20013078.2020.1795362

214. Adedeji AO, Severson W, Jonsson C, Singh K, Weiss SR, Sarafianos SG. Novel Inhibitors of Severe Acute Respiratory Syndrome Coronavirus Entry That Act by Three Distinct Mechanisms. J Virol (2013) 87:8017-28. doi: 10.1128/jvi.00998-13

215. Sanders JM, Monogue ML, Jodlowski TZ, Cutrell JB. Pharmacologic Treatments for Coronavirus Disease 2019 (COVID-19): A Review. JAMA (2020) 323:1824-36. doi: 10.1001/jama.2020.6019

216. Sur S, Khatun M, Steele R, Isbell TS, Ray R, Ray RB. Exosomes From COVID-19 Patients Carry Tenascin-C and Fibrinogen- $\beta$ in Triggering Inflammatory Signals in Cells of Distant Organ. Int J Mol Sci (2021) 22. doi: 10.3390/ijms22063184

217. Hanna R, Dalvi S, Sălăgean T, Pop ID, Bordea IR, Benedicenti S. Understanding COVID-19 Pandemic: Molecular Mechanisms and Potential Therapeutic Strategies. An Evidence-Based Review. J Inflammation Res (2021) 14:13-56. doi: 10.2147/jir.S282213

218. Gordon DE, Hiatt J, Bouhaddou M, Rezelj VV, Ulferts S, Braberg H, et al. Comparative Host-Coronavirus Protein Interaction Networks Reveal PanViral Disease Mechanisms. Science (2020) 370. doi: 10.1126/science.abe9403

219. He C, Zheng S, Luo Y, Wang B. Exosome Theranostics: Biology and Translational Medicine. Theranostics (2018) 8:237-55. doi: 10.7150/ thno.21945 
220. Elahi FM, Farwell DG, Nolta JA, Anderson JD. Preclinical Translation of Exosomes Derived From Mesenchymal Stem/Stromal Cells. Stem Cells (2020) 38:15-21. doi: 10.1002/stem.3061

221. Guan S, Li Q, Liu P, Xuan X, Du Y. Umbilical Cord Blood-Derived Dendritic Cells Loaded With BGC823 Tumor Antigens and DC-Derived Exosomes Stimulate Efficient Cytotoxic T-Lymphocyte Responses and Antitumor Immunity In Vitro and In Vivo. Cent Eur J Immunol (2014) 39:142-51. doi: $10.5114 /$ ceji.2014.43713

222. Mulcahy LA, Pink RC, Carter DR. Routes and Mechanisms of Extracellular Vesicle Uptake. J Extracell Vesicles (2014) 3. doi: 10.3402/jev.v3.24641

223. Wang H, Zheng R, Chen Q, Shao J, Yu J, Hu S. Mesenchymal Stem Cells Microvesicles Stabilize Endothelial Barrier Function Partly Mediated by Hepatocyte Growth Factor (HGF). Stem Cell Res Ther (2017) 8:211. doi: 10.1186/s13287-017-0662-7

224. Park HJ, Shin JY, Kim HN, Oh SH, Song SK, Lee PH. Mesenchymal Stem Cells Stabilize the Blood-Brain Barrier Through Regulation of Astrocytes. Stem Cell Res Ther (2015) 6:187. doi: 10.1186/s13287-015-0180-4

225. Xian P, Hei Y, Wang R, Wang T, Yang J, Li J, et al. Mesenchymal Stem CellDerived Exosomes as a Nanotherapeutic Agent for Amelioration of Inflammation-Induced Astrocyte Alterations in Mice. Theranostics (2019) 9:5956-75. doi: 10.7150/thno.33872

226. Tang XJ, Sun XY, Huang KM, Zhang L, Yang ZS, Zou DD, et al. Therapeutic Potential of CAR-T Cell-Derived Exosomes: A Cell-Free Modality for Targeted Cancer Therapy. Oncotarget (2015) 6:44179-90. doi: 10.18632/ oncotarget.6175

227. Fu W, Lei C, Liu S, Cui Y, Wang C, Qian K, et al. CAR Exosomes Derived From Effector CAR-T Cells Have Potent Antitumour Effects and Low Toxicity. Nat Commun (2019) 10:4355. doi: 10.1038/s41467-019-12321-3

228. Tumne A, Prasad VS, Chen Y, Stolz DB, Saha K, Ratner DM, et al. Noncytotoxic Suppression of Human Immunodeficiency Virus Type 1
Transcription by Exosomes Secreted From CD8+ T Cells. J Virol (2009) 83:4354-64. doi: 10.1128/jvi.02629-08

229. Nojehdehi S, Soudi S, Hesampour A, Rasouli S, Soleimani M, Hashemi SM. Immunomodulatory Effects of Mesenchymal Stem Cell-Derived Exosomes on Experimental Type-1 Autoimmune Diabetes. J Cell Biochem (2018) 119:9433-43. doi: 10.1002/jcb.27260

230. Cho BS, Kim JO, Ha DH, Yi YW. Exosomes Derived From Human Adipose Tissue-Derived Mesenchymal Stem Cells Alleviate Atopic Dermatitis. Stem Cell Res Ther (2018) 9:187. doi: 10.1186/s13287-018-0939-5

231. Lee BC, Kang I, Yu KR. Therapeutic Features and Updated Clinical Trials of Mesenchymal Stem Cell (MSC)-Derived Exosomes. J Clin Med (2021) 10. doi: $10.3390 /$ jcm 10040711

Conflict of Interest: The authors declare that the research was conducted in the absence of any commercial or financial relationships that could be construed as a potential conflict of interest.

Publisher's Note: All claims expressed in this article are solely those of the authors and do not necessarily represent those of their affiliated organizations, or those of the publisher, the editors and the reviewers. Any product that may be evaluated in this article, or claim that may be made by its manufacturer, is not guaranteed or endorsed by the publisher.

Copyright (c) 2021 Gurunathan, Kang and Kim. This is an open-access article distributed under the terms of the Creative Commons Attribution License (CC BY). The use, distribution or reproduction in other forums is permitted, provided the original author(s) and the copyright owner(s) are credited and that the original publication in this journal is cited, in accordance with accepted academic practice. No use, distribution or reproduction is permitted which does not comply with these terms. 